\title{
LA CRISIS FINANCIERA EN ASIA: ORÍGENES Y \\ EVOLUCIÓN EN 1997 Y 1998
}

\author{
Rafael del Villar* \\ José Antonio Murillo \\ Daniel Backal
}

Diciembre de 1998

\section{Documento de Investigación No. 9807 \\ Dirección General de Investigación Económica \\ Banco de México}

\footnotetext{
*Mucho agradecemos a Johanna Gil por su dedicación y gran apoyo para la elaboración de este documento. También agradecemos la asistencia de Jaime Calleja, Ana Saavedra y Luis Treviño. Los valiosos comentarios de Agustín Carstens, Moisés Schwartz y Alejandro Díaz de León ayudaron mucho a mejorar este documento.
} 


\title{
LA CRISIS FINANCIERA EN ASIA: ORÍGENES Y EVOLUCIÓN EN 1997 Y 1998
}

\author{
Rafael del Villar \\ José Antonio Murillo \\ Daniel Backal
}

Diciembre de 1998

D ocumento de Investigación 9807

\section{RESUMEN}

La crisis financiera que estalla inicialmente en Tailandia en julio de 1997, se ha extendido a nivel regional y global. La crisis ha provocando serias repercusiones económicas, políticas y sociales en Corea, Indonesia, Malasia, Tailandia e incluso, aunque en menor medida, en Japón. La crisis asiática ha tenido una severidad tal que a nivel global ha generado una caída importante en el crecimiento económico mundial y ha afectado la estabilidad del sistema financiero. Las repercusiones han sido especialmente severas en los países de América Latina. Este documento analiza en forma detallada las causas de la crisis y su evolución, así como una descripción de los avances en la resolución de la misma durante 1997 y 1998 en Japón, Corea del Sur, Indonesia, Malasia y Tailandia. 


\section{Indice}

$\begin{array}{lll}\text { 1.- Introducción } & \text { Pg. } 5\end{array}$

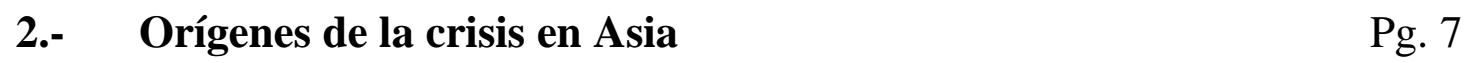

$\begin{array}{ll}\text { 2.1 Causas Externas } & \text { Pg. } 7\end{array}$

Efecto Contagio

Endeudamiento Externo

Términos de Intercambio

Cuenta Corriente

2.2 Causas Internas

Pg. 10

Burbujas en Precios de Activos

Inestabilidad Política

2.3 Desregulación Financiera y Controles Internos $\quad$ Pg. 12

Desregulación Financiera

Controles Internos

2.4 Supervisión y Regulación

Pg. 13

Supervisión

Regulación

$\begin{array}{ll}\text { 3.- } & \text { Medidas para Enfrentar la Crisis }\end{array}$

3.1 Aspectos Generales

Pg. 17

Prestamista de Ultima Instancia a Nivel Internacional

Intervención de Instituciones Financieras

Seguro de Depósitos

Relajamiento de la Regulación Bancaria al Estallar la Crisis

3.2 Medidas de Saneamiento

Pg. 22

3.3 Acciones para Resolver la Crisis Financiera:

El Caso de Japón

Pg. 24

Reforma y Capitalización del Seguro de Depósitos

Aumento de los Recursos Públicos para Combatir

la Crisis Financiera 
4.- Fortalecimiento del Marco Regulatorio y de Supervisión

Pg. 27

4.1 Fortalecimiento de la Regulación Prudencial

Pg. 27

4.2 Diversificación de la Cartera

Pg. 28

4.3 Desregulación Financiera

Pg. 29

4.4 Ley de Quiebras

Pg. 30

4.5 Fortalecimiento de la Autoridad de Supervisión

Pg. 30

4.6 Auditorías

Pg. 31

4.7 Autonomía del Banco Central

Pg. 31

5.- Costos Fiscales de la Crisis

Pg. 32

5.1 Japón

Pg. 32

5.2 Tailandia

Pg. 32

5.3 Malasia

Pg. 32

5.4 Corea

Pg. 33

5.5 Indonesia

Pg. 33

6.- Conclusiones

Pg. 33

6.1. Lecciones de la Crisis Asiática

Pg. 34

Bibliografía

Pg. 37

Anexo Cuadros de Crisis Financieras en Corea,

Indonesia, Japón, Malasia y Tailandia.

Pg. 43 


\section{Introducción}

A mediados de 1997 estalla en Asia (orea, Indonesia, Japón, Malasia y Tailandia) una de las crisis financieras y económicas de mayor profundidad que se han observado desde la Segunda Guerra Mundial (ver cuadro 1). La virulencia de la crisis asiática ha sorprendido y repercutido en el mundo entero. Las perspectivas actuales de crecimiento para la región son desfavorables. El crecimiento estimado para 1998 es: $-18.5 \%$ para Indonesia, $-7 \%$ para Corea, $-5.8 \%$ para Malasia, $-7 \%$ para Tailandia y $-1.9 \%$ para Japón ${ }^{1}$. Asimismo, los analistas financieros esperan que en 1999 el crecimiento en la región continúe siendo negativo. ${ }^{2}$ Adicionalmente, las proyecciones de la OCDE en cuanto a crecimiento mundial se ajustaron a la baja en un $1 \%$ como consecuencia de las crisis de Asia.

El objetivo de este estudio es describir el avance que existe en la resolución de la crisis financiera en Corea, Indonesia, Japón, Malasia y Tailandia. Las crisis en estos países son distintas y obedecen a un gran número de factores que se conjuntan y retroalimentan. El análisis que se presenta en este documento trata de ofrecer una visión detallada de las distintas causas y medidas que se han adoptado para hacer frente a las crisis.

\section{Cuadro 1}

\section{Evolución del Tipo de Cambio y del Indice Bursátil de Países Asiáticos entre el $1^{\circ}$ julio de 1997 y el 29 de octubre de 1998}

\begin{tabular}{|c|c|c|c|}
\hline & PAISES & $\begin{array}{c}\text { VARIACION DEL TIPO DE } \\
\text { CAMBIO* }\end{array}$ & $\begin{array}{l}\text { VARIACIONES DEL } \\
\text { INDICE BURSATIL** }\end{array}$ \\
\hline \multirow{5}{*}{$\begin{array}{l}\text { PAISES } \\
\text { EN } \\
\text { CRISIS }\end{array}$} & JAPON & $-1.46 \%$ & $-32.77 \%$ \\
\hline & COREA DEL SUR & $49.15 \%$ & $-44.04 \%$ \\
\hline & MALASIA & $44.16 \%$ & $-63.44 \%$ \\
\hline & TAILANDIA & $16.06 \%$ & $-48.16 \%$ \\
\hline & INDONESIA & $180.77 \%$ & $-57.10 \%$ \\
\hline \multirow{5}{*}{$\begin{array}{l}\text { OTROS } \\
\text { PAISES } \\
\text { ASIATICOS }\end{array}$} & CHINA & $-0.15 \%$ & $3.77 \%$ \\
\hline & FILIPINAS & $40.48 \%$ & $-36.21 \%$ \\
\hline & HONG KONG & $0.07 \%$ & $-39.32 \%$ \\
\hline & SINGAPUR & $10.15 \%$ & $-39.20 \%$ \\
\hline & TAIWAN & $16.05 \%$ & $-30.29 \%$ \\
\hline
\end{tabular}

\footnotetext{
${ }^{1}$ El Fondo Monetario Internacional estimaba a finales de noviembre de 1998 que la economía japonesa se reduciría al menos 3\% durante el año fiscal de 1998 que termina en marzo de 1999.

${ }^{2}$ Ver Goldman Sachs, julio 1998.
} 
Se puede señalar que la crisis de Tailandia, y en menor medida la de Corea, se explican por una política económica insostenible. En estos países las autoridades establecieron un régimen de tipo de cambio predeterminado. La garantía cambiaria incentivó un excesivo endeudamiento externo, en particular, de corto plazo. La problemática descrita aumentó debido a una regulación y supervisión financiera inadecuada que permitió a los bancos y otras instituciones financieras asumir riesgos cambiarios y crediticios elevados. Además, la debilidad de la economía japonesa y el deterioro de los términos de intercambio de los países descritos contribuyeron al deterioro de su situación económica.

La crisis en Indonesia es más profunda dado que la crisis financiera desemboca en una crisis política. Se trata de un país que inicia la crisis financiera en un entorno en que las instituciones se debilitan con la incertidumbre política, alimentada en un inicio por el deterioro de la salud del presidente Suharto; una sequía devastadora que empobrece a la población rural y una sociedad fracturada por el resurgimiento de conflictos étnicos. Además, Indonesia sufre una importante disminución en sus ingresos por la caída en los precios del petróleo.

La crisis de Malasia se explica en buena medida por el contagio de las crisis de los países vecinos. Malasia es un país que a raíz de la crisis que experimentó a mediados de los ochenta, adecuó a estándares internacionales buena parte del marco regulatorio y de supervisión financiero. Además, como resultado de la inestabilidad financiera del exterior, Malasia se ha visto perjudicada por un deterioro en el precio de sus productos de exportación. Sin embargo, la crisis financiera pudiera convertirse en una crisis política debido a la renuncia del Gobernador del Banco Central Ahmad Mohamed Don y del Subgobernador Fong Weng Phak, así como la destitución y encarcelamiento del Ministro de Finanzas Anwar Ibrahim. Adicionalmente, el efecto de la imposición de controles de capital y de la transición a un régimen cambiario rígido todavía es incierto.

La crisis de Japón tiene su origen en la burbuja especulativa que inició en 1986 y se rompe en 1990. Durante la época de la burbuja los créditos se concentraron en el sector de bienes raíces, mientras que las instituciones financieras destinaron una buena parte de su capital para la adquisición de acciones bursátiles. El rompimiento de la burbuja ocasionó un deterioro paulatino en la salud de los bancos, tanto por la disminución en el valor del colateral de su cartera y de sus activos, como por la desaceleración del crecimiento económico. La resolución de la crisis financiera se ha prolongado, en buena medida, por la creencia de que los problemas de los bancos los tienen que resolver los propios banqueros y la reticencia de la sociedad japonesa a destinar recursos públicos al apoyo de las instituciones financieras en problemas.

La organización del documento es la siguiente: En la segunda sección se presentan las principales causas de la crisis. En la tercera sección se analizan las distintas medidas que los países adoptaron para su resolución. En la cuarta sección se discuten las reformas estructurales que se han llevado a cabo hasta la fecha. Finalmente se presentan algunas estimaciones de los costos fiscales de las crisis. 


\section{Orígenes de la Crisis en Asia}

El objetivo de esta sección es resaltar algunos aspectos relevantes sobre los orígenes de las crisis que sean útiles para entender las medidas correctivas que se adoptaron posteriormente, por lo que esta sección no pretende ser exhaustiva. ${ }^{3}$

Las causas de la crisis en los países del Sudeste Asiático se pueden dividir en macroeconómicas y microeconómicas. Los orígenes macroeconómicos son tanto de índole interno como externo. Entre las causas externas, la más importante es el efecto contagio y el gran endeudamiento externo de corto plazo por parte de bancos y empresas. Entre las causas macroeconómicas internas, la más importante es la gestación de burbujas en precios de activos (bienes raíces y acciones) que, junto con una deficiente regulación y supervisión del sistema financiero, contribuyó al endeudamiento excesivo y a una inadecuada diversificación de la cartera de los bancos. Aunado a lo anterior, varios países en Asia sufrieron una creciente inestabilidad política que culminó en cambios de gobierno en Indonesia y Tailandia durante 1997 y en Japón durante 1998. En particular, en Indonesia la situación política y social se ha deteriorado drásticamente, siendo éste el principal factor que explica la magnificación de la crisis financiera. Esta inestabilidad tuvo el efecto de mantener las tasas de interés en niveles elevados, y de retrasar la adopción de medidas para enfrentar la crisis. La parte microeconómica se puede dividir en una desregulación financiera que vino acompañada de una supervisión y regulación inadecuada y en una mala administración interna de los bancos.

\subsection{Causas Externas}

\subsubsection{Efecto Contagio}

El efecto macroeconómico común a los cinco países analizados es el efecto contagio. Tras un ataque especulativo sobre el baht, Tailandia deja flotar su moneda en julio de $1997 .{ }^{4}$ A esta devaluación siguieron episodios similares unas semanas después en Malasia e Indonesia. Indonesia decide abandonar la banda cambiaria el 14 de agosto de 1997 tras un ataque especulativo contra la rupía. A medida que se conocen las debilidades del sector financiero y el alto endeudamiento externo e interno de las empresas, los participantes en el mercado cambiario y de dinero corren en contra de la moneda local, lo que ocasiona una mayor devaluación. En Malasia, entre julio y agosto de 1997, el ringgit se deprecia en un 50\%. Esta situación se complica con la caída de la bolsa de valores de Hong Kong en octubre de 1997, lo cual desató presiones especulativas sobre el won de Corea y el yen japonés. Entre octubre y diciembre de 1997, el won se deprecia $30 \%$ y el yen pierde contra el dólar un $10 \%$ de su valor (ver gráficas 1 y 2).

\footnotetext{
${ }^{3}$ Para un análisis detallado ver Takatoshi Ito (1997), Akira Nagashima (1997), Radelet y Sachs (1998a) y (1998b), y Javad Shirazi (1998).

${ }^{4}$ La causa inmediata del ataque especulativo sobre el baht radica en la quiebra de compañías financieras que concentraron préstamos en el sector de bienes raíces, a la apreciación del yen frente al dólar en los meses previoslo que causó una perdida de competitividad- y a la caída de los precios de sus principales mercancías de exportación.
} 


\section{Gráfica 1}

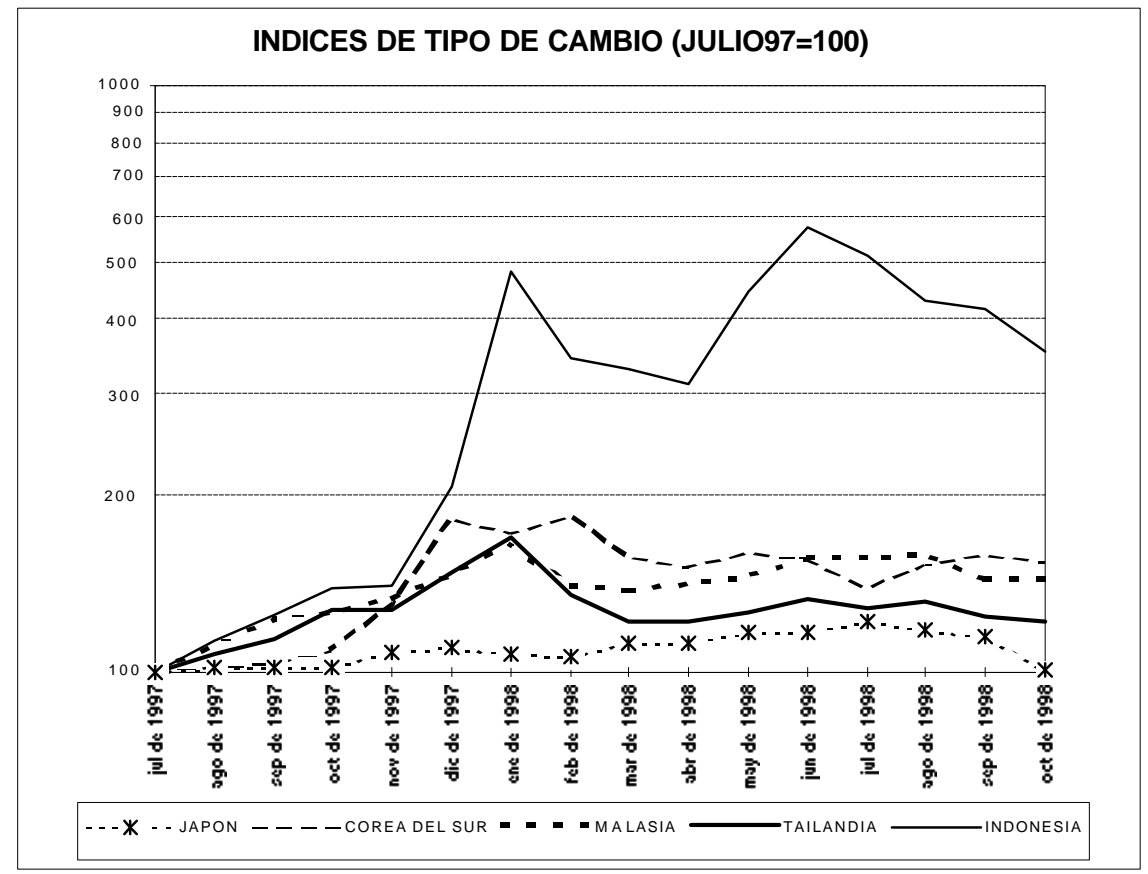

\section{Gráfica 2}

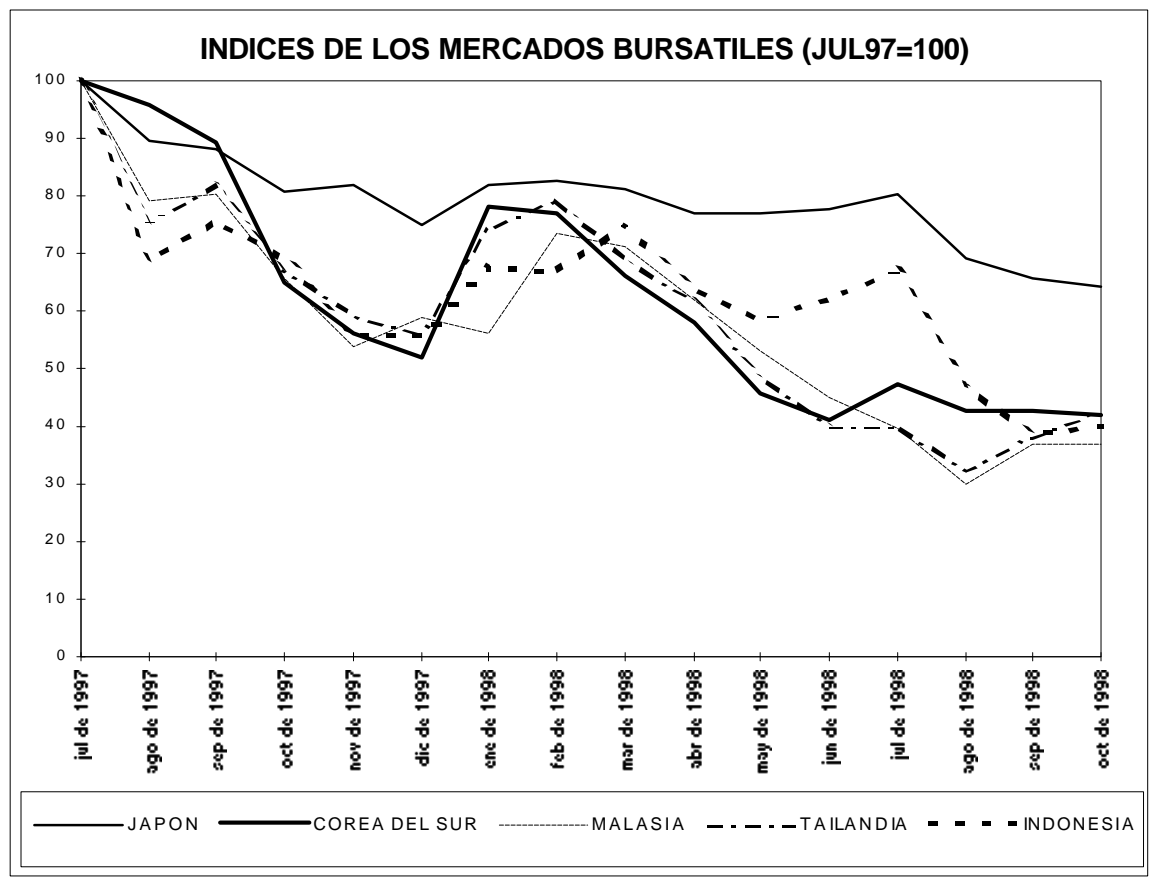


Esta situación impactó adversamente a las instituciones de crédito de los países en crisis. La devaluación de sus monedas aumentó el costo del financiamiento externo bancario, el cual ya era elevado y en gran medida de corto plazo en varios de estos países. ${ }^{5}$ La devaluación aumentó significativamente el valor en moneda nacional de la deuda denominada en moneda extranjera y los acreedores internacionales en muchas ocasiones no renovaron las líneas de crédito. Las alzas de las tasas de interés internas y las caídas de las bolsas de valores también afectaron adversamente a las instituciones de crédito.

En respuesta a la incertidumbre y a la especulación sobre la cotización de sus monedas, los países asiáticos (excepto Japón) recurrieron a políticas monetarias restrictivas para aminorar las presiones sobre el tipo de cambio. Esto se observa principalmente en Indonesia, país en el que la tasa de fondeo llegó a 81\%. En Malasia, la tasa de depósito bancario a un mes aumentó 300 puntos base durante julio de 1997, y en Tailandia esta tasa de interés aumentó 400 puntos base en el mismo periodo. El aumento de las tasas de interés dificultó el pago de los créditos por lo que la cartera vencida de los bancos aumentó considerablemente.

Las caídas de los índices bursátiles han impactado severamente a los bancos comerciales de Corea y Japón, ya que éstos tienen invertido una parte considerable de su capital en títulos bursátiles. La caída de la bolsa de valores de Corea que supera el $50 \%$, en el periodo junio de 1997-julio de 1998, exacerbó la erosión del capital básico de los bancos. En Japón, la bolsa cayó un 40\% entre junio de 1997 y enero de 1998.

\subsubsection{Endeudamiento Externo}

El endeudamiento externo de corto plazo es un problema para todos los países analizados, aunque para Japón y Malasia este problema se presenta en menor medida. Los agentes económicos no cubrieron sus posiciones ante posibles cambios abruptos en el valor de la paridad. Además, la amortización acelerada de dicha deuda que exigieron los acreedores externos al inicio de la crisis generó problemas serios de liquidez en las empresas y en el sistema financiero.

Los orígenes del excesivo endeudamiento externo se pueden encontrar en una visión internacional demasiado optimista de los "Tigres Asiáticos", en una desregulación inadecuada de la cuenta de capitales y del sistema financiero ${ }^{6}$ y en políticas cambiarias que otorgaban una garantía implícita sobre el valor de la moneda que incentivaron al sector privado a endeudarse fuertemente en moneda extranjera sin cubrir el riesgo cambiario ${ }^{7}$.

En Indonesia, la deuda externa privada creció de manera significativa a partir de 1992. Entre 1992 y 1997 el 85\% del crecimiento en la deuda externa se debió a créditos privados. Además, una parte importante de este endeudamiento era a corto plazo. El plazo promedio de los créditos en 1997 era de 18 meses, y el cociente de deuda privada de corto plazo respecto al nivel de reservas internacionales era de 1.8 veces. En Corea, desde principios de los noventa se dio un fuerte endeudamiento externo privado tanto de bancos como de empresas. En Tailandia, para 1997, el 34\% de la deuda externa privada era de corto plazo. En Malasia, sin embargo, la

\footnotetext{
${ }^{5}$ Tal es el caso de Corea (60\% de la deuda externa privada era de corto plazo en 1997), Tailandia (34\% del endeudamiento externo de las empresas era a corto plazo) e Indonesia.

${ }^{6}$ La desregulación de la cuenta de capitales que se dio en Tailandia a principios de los noventa resultó en una fuerte entrada de capitales. En el periodo 1994-96, las entradas de capitales promediaron 15.4\% del PIB anualmente.

${ }^{7}$ Los países que contaban con algún régimen cambiario predeterminado eran Corea, Indonesia, y Tailandia.
} 
deuda externa total como porcentaje del PIB es pequeña comparada con otros países de la región (40\% del PIB para 1997) y sólo el $20 \%$ era a corto plazo.

Cabe destacar que el retiro de las líneas de crédito por parte de la banca comercial contribuyó al estallido de la crisis. Esto ocurrió particularmente en el caso de Corea, país en el que el fuerte endeudamiento externo de corto plazo no pudo ser refinanciado. Los bancos internacionales no renovaron las líneas de crédito a bancos y conglomerados industriales, lo cual generó problemas de liquidez. Este retiro de líneas de crédito pudo haber estado asociado al recrudecimiento de la crisis en Japón a mediados de 1997, ya que forzó a los bancos japoneses (uno de los principales acreedores de las empresas coreanas) a retirar créditos para cumplir con sus requisitos de capitalización.

\subsubsection{Términos de Intercambio}

En adición a los factores ya señalados, a partir de 1997 los países asiáticos citados también experimentan un deterioro en sus términos de intercambio. Durante 1997, Corea sufre un deterioro de $20 \%$ en sus términos de intercambio, el cual se debe en buena parte a la disminución en el precio de los semiconductores. Asimismo, los términos de intercambio de Indonesia han tenido un fuerte declive ante la caída de 30\% que se ha registrado en los precios del petróleo durante 1998. También, durante 1997-98, Malasia sufre una baja en el precio de los productos electrónicos (una de sus principales exportaciones).

\subsubsection{Cuenta Corriente}

La cuenta corriente no fue un factor importante para países como Indonesia y Corea, ya que tenían déficit en cuenta corriente relativamente pequeños. Este déficit como proporción del PIB para 1997 es de $2.9 \%$ para Indonesia y de $2.8 \%$ para Corea. Sin embargo, Tailandia y Malasia mantenían déficit en cuenta corriente elevados antes de la crisis. Para Tailandia, el déficit de la cuenta corriente como proporción del PIB en 1996 es de $7.9 \%$, el cual se reduce a 3.9\% en 1997. Malasia presenta un déficit de cuenta corriente de 10\% del PIB en 1995, el cual se reduce a $4.9 \%$ en 1996; sin embargo, el déficit para 1997 volvió a incrementarse (5.8\% del PIB).

\subsection{Causas Internas}

\subsubsection{Burbujas en Precios de Activos}

El surgimiento de burbujas en precios de activos (acciones y bienes raíces) con anterioridad a la crisis se presenta en mayor o menor medida en todos los países. El rápido aumento en el precio de los activos tiene un doble efecto. Primero, ante las mayores ganancias en el sector (ya sea bienes raíces o acciones), los inversionistas y los bancos destinan más recursos hacia ese sector. Esto hace que aumenten aún más los precios y que el valor del colateral del deudor sea mayor y que de esa forma éste pueda obtener mayores créditos. El rompimiento de la burbuja tiene consecuencias adversas sobre la calidad de los portafolios de los bancos y sobre la demanda agregada. Además, es común que se mantenga una concentración elevada de créditos en los sectores en donde se produce dicha burbuja (típicamente construcción y bienes raíces) ${ }^{8}$.

La primera burbuja en precios se observa en Japón. La política monetaria expansiva adoptada a partir de 1986 y hasta finales de la década tuvo como objetivo evitar una mayor apreciación del

\footnotetext{
${ }^{8}$ Tal es el caso de Corea, $\underline{\text { Japón, }}$ Malasia y $\underline{\text { Tailandia. }}$
} 
yen, que se consideraba tendría efectos adversos sobre la competitividad del país. Parte del surgimiento de la burbuja especulativa se debió a dicha política monetaria. Sin embargo, la implantación de una política monetaria restrictiva a partir de 1990 trajo como consecuencia una baja acelerada de los precios de los activos y de los bienes raíces. El rompimiento de la burbuja especulativa trajo como consecuencia una reducción significativa en la demanda agregada (menor consumo privado y una menor inversión debido en parte también a la sobreinversión que se registró durante los ochenta), y un continuo deterioro en la calidad de los activos del sistema financiero.

Las burbujas en Tailandia y Malasia empiezan a partir de 1993. La burbuja en Malasia empezó en 1993 y se rompió en 1997; en el periodo 1994-1996, los precios de las casas aumentaron en $40 \%$, y la bolsa de valores aumentó en $25 \%$ durante ese mismo periodo. En Tailandia se dio una importante burbuja especulativa a partir de 1993. Los orígenes de esta burbuja se encuentran en un tipo de cambio que incentivó la entrada de capitales y el endeudamiento externo. Entre 1995 y 1996, el área permitida para construir en Bangkok se redujo en 60\%, y la bolsa de valores aumentó $63.4 \%$ en el periodo 1993-95, para luego caer en más del 90\% durante el periodo 1996-97.

\subsubsection{Inestabilidad Política}

La inestabilidad política puede ser vista a la vez como causa y consecuencia de la crisis en Asia. Muchos de los choques políticos que se dieron sucedieron solo poco tiempo después de que empezó la crisis por lo que puede decirse que crisis e inestabilidad política marchan de la mano y se alimentan mutuamente, generando entre sí un círculo vicioso.

La inestabilidad política tiene el efecto de mantener elevados los niveles de las tasas de interés domésticas, retrasar la adopción de medidas estructurales para enfrentar la crisis, y prolongar el periodo en el que se adoptan las medidas iniciales.

Hasta diciembre de 1997 el gobierno indonesio había logrado contener la magnitud de la crisis (la devaluación en el periodo de julio a diciembre fue de 40\%). Sin embargo, en diciembre hay un marcado deterioro debido a la pobre salud del presidente Suharto y dudas sobre la continuidad del régimen. Entre diciembre y enero la rupia se devalúa casi un $300 \%$ adicional. Además de la corrida sobre la moneda, también se observan corridas bancarias. Después de 30 años en el poder, la posible salida de Suharto crea un vacío institucional que se refleja en una gran incertidumbre sobre el futuro del país. La situación se vuelve a deteriorar el 14 de mayo con las revueltas en Jakharta, en las que salió a relucir un conflicto étnico entre la población general y la minoría prospera de origen chino. Los indonesios de origen chino sufrieron ataques a su persona y a sus propiedades. En estas revueltas murieron 1,200 personas, la mayoría de origen chino. Esto ha provocado una fuerte salida de capitales, así como la emigración de miembros de la comunidad china, con un alto nivel económico. El nombramiento del presidente Habibie, en mayo de 1998, no ha brindado suficiente estabilidad, pues éste tiene fuertes nexos con el gobierno de Suharto.

En Japón, el Primer Ministro renuncia en julio de 1998 ante presiones por la falta de acción para solucionar el problema bancario. La reciente elección del Primer Ministro Keizo Obuchi pudiera coadyuvar a una solución del problema bancario. En Tailandia, a raíz de la crisis, el gobernador del banco central y el primer ministro tienen que renunciar. El nuevo gobierno entra en noviembre de 1997. 
En Malasia, en septiembre de 1998 el Primer Ministro Mahathir Mohamad por primera vez en 17 años enfrenta oposición en la sociedad y dentro de su mismo gabinete. El gobernador del Banco Central Ahmad Mohamed Don y el Subgobernador Fong Weng Phak, quienes habían sido partidarios de una política monetaria restrictiva para controlar la inflación, renuncian a sus puestos. Por otra parte, el Primer Ministro destituye y encarcela al Ministro de Finanzas Anwar Ibrahim, otrora candidato a suceder al Primer Ministro, bajo cargos de sodomía y corrupción, lo que provoca nutridas manifestaciones en su apoyo y en rechazo a Mahathir Mohamad.

\subsection{Desregulación Financiera y Controles Internos}

\subsubsection{Desregulación Financiera}

La desregulación financiera, cuando no es acompañada de una supervisión más estricta y un marco regulatorio adecuado, es comúnmente citada como una de las principales causas de las crisis financieras ${ }^{9}$. Este es el caso de países tan diversos como Estados Unidos (1982-1991), Japón (1990- ) y Suecia (1991). En el caso de Asia, la desregulación financiera previa a la crisis no es un factor común a todos los países y presenta distintas modalidades.

En particular, cabe destacar la liberalización de la cuenta de capitales vía la desregulación de los controles de crédito de corto plazo o de los límites prudenciales al endeudamiento externo de los bancos. Este tipo de desregulación permite que los bancos ofrezcan créditos en moneda extranjera relativamente baratos a corto plazo. Tal es el caso de Corea que, con la intención de apoyar al comercio internacional, durante 1993 eliminó los controles al crédito de corto plazo. El resultado fue un endeudamiento corporativo de corto plazo en moneda extranjera excesivo. En Japón, en 1984 se disminuyen los límites de las obligaciones que los bancos pueden incurrir en moneda extranjera. En Tailandia, los bancos podían ofrecer créditos en moneda extranjera a deudores domésticos. Esto explica porque en Tailandia la deuda externa corporativa no era tan alta pues la mayoría de las empresas se endeudaban con bancos tailandeses que prestaban en moneda extranjera. Cabe destacar que la regulación no obligaba a los bancos a cubrir sus posiciones en moneda extranjera.

\subsubsection{Controles Internos}

Un problema común a todos los países bajo estudio tiene que ver con cuestiones de administración interna. Estos problemas provienen de un control de riesgos inadecuado y de la relación entre bancos y grandes conglomerados industriales.

La falta de un adecuado control interno de riesgos en los bancos y empresas provoca problemas de concentración de créditos, y la existencia de prácticas grises e incluso fraudulentas. Usualmente, la concentración de créditos se da en el sector bienes raíces y en la compra de acciones. En Japón, la estructura de la organización de los bancos debilitó la función de

\footnotetext{
9 Ver, por ejemplo, Banking Crisis: Cases and Issues, Sundararajan V. y Tomás J. T. Baliño (eds,) International Monetary Fund, Washington, 1991; Bank Insolvencies: Cross Country Experiences, Caprio, Gerard y Daniela Klingebiel World Bank, Washington, julio, 1996. Banking Crises in Latin America, Hausmann, Ricardo y Liliana Rojas-Suárez (eds.), Inter-American Development Bank, Washington, 1996; Bank Restructuring: Lessons from the 1980's, Sheng, Andrew (ed.), World Bank, Washington, 1996.
} 
auditoría interna. Además, en Japón no existía una adecuada evaluación y administración de los riesgos inherentes a los activos más riesgosos. Los bancos ampliaron su portafolio en bienes raíces que estos erróneamente consideran de bajo o nulo riesgo. La concentración de créditos en el sector de bienes raíces y de acciones se observa también en Malasia y Tailandia ${ }^{10}$. En Corea, la concentración crediticia no ocurre tanto en el sector de bienes raíces, sino que más bien se trata de una concentración por cliente. La mayor parte de los bancos concentraron sus créditos en unos cuantos conglomerados industriales (chaebols); existen 59 chaebols, y se estima que las deudas de los 5 chaebols de mayor tamaño representan $40 \%$ del problema bancario y las deudas de los siguientes 10 chaebols otro $30 \%$ del problema.

Los nexos existentes entre bancos y grandes conglomerados industriales en Corea y Japón, propician que los créditos no siempre se otorguen para financiar los proyectos más productivos y que la salud del banco este estrechamente ligada a la salud del conglomerado al que pertenece. En Corea, los conglomerados son dueños de bancos comerciales y estos a su vez invierten su capital en acciones de los mismos conglomerados. Esta relación se ilustra mejor con la quiebra de los chaebols que se da al inicio de la crisis. En enero de 1997 quiebra el primer conglomerado industrial en una década, "Aceros Hanbo" con una deuda de 6 mil millones de dólares. En los meses siguientes también quiebran Motores Kia y Aceros Sammi. Las bancarrotas crearon una fuerte presión sobre los bancos mercantiles, pues una buena parte de los créditos externos que recibieron estos chaebols se habían canalizado, y en algunos casos fueron garantizados, por estos bancos. ${ }^{11}$ En Japón, las grandes empresas son accionistas de los bancos e invierten parte de sus recursos en acciones de las empresas por lo que al caer la bolsa también cae el capital de los bancos. Esto hace que el futuro del banco este estrechamente ligado a la salud de la empresa en la cuál tiene invertido su capital y gran parte de su portafolio crediticio. En Malasia, la administración interna de los bancos es relativamente buena. Sin embargo, muchos bancos pertenecen a conglomerados industriales y, a su vez, los bancos tienen una participación importante dentro de las compañías financieras (que son las que se encuentran en peor situación).

\subsection{Supervisión y Regulación}

En la mayoría de los países analizados, el marco regulatorio era inadecuado y la supervisión era débil. Lo anterior permitió la concentración excesiva de créditos, la falta de transparencia y el continuo deterioro de los activos de los bancos. Un reflejo adicional de la insuficiencia regulatoria y de supervisión es el excesivo crecimiento crediticio que se observó antes de la crisis.

En Corea, en el periodo de 1991 a 1997 el crédito interno creció a una tasa real de 13\% anual, muy superior a la tasa de la producción. . Una situación similar ocurre en Indonesia ya que en el periodo de 1991 a 1997 el crédito interno creció a una tasa real de 12\% anual. En Malasia, en 1996 y 1997, el crédito creció a una tasa real de $26 \%$ anual. En Tailandia, los créditos de los bancos comerciales aumentaron en $76 \%$ en términos reales de 1993 a 1996, y para el mismo periodo, los créditos de las compañías financieras al sector privado aumentaron en $85 \%$ en

\footnotetext{
${ }^{10}$ En Malasia, el $30 \%$ de los créditos de los bancos se concentran en el sector bienes raíces y el $15 \%$ en créditos para la compra de acciones.

${ }^{11}$ Cabe destacar que el problema en Corea es mucho más grave dado el alto endeudamiento de los conglomerados industriales (la razón deuda a capital es de alrededor de 400\%).
} 
términos reales.

En este contexto, es importante mencionar que la profundidad financiera en Asia es mucho mayor que en América Latina. Esto tiene como consecuencia que la cartera vencida en Asia represente un problema mayor para la economía en su conjunto, ya que los créditos del sector financiero al sector privado representan un porcentaje del PIB mucho mayor. En 1997, en Corea los créditos al sector privado representaron 140\% del PIB para 1997, en Indonesia el $65 \%$, en Malasia el 160\%, y en Tailandia el 130\%. Según datos reportados en octubre de 1998, en Japón los 19 bancos más grandes han otorgados créditos equivalentes al 74\% del PIB.

\subsubsection{Supervisión}

La inadecuada supervisión permitió que bancos con bajos niveles de capitalización siguieran operando. Las deficiencias en la supervisión también facilitaron la concentración excesiva de créditos, el otorgamiento de créditos relacionados y la falta de transparencia sobre la salud de los bancos. Como ejemplo de lo anterior, cabe destacar los casos de Indonesia y Japón.

En Indonesia, la regulación del Banco Central sobre préstamos relacionados, concentración del crédito y criterios para la evaluación de crédito se aplicaron inadecuadamente; dichas reglas se transgredían de manera recurrente sin sanción alguna. Antes del inicio de la crisis varios bancos se encontraban subcapitalizados, algunos de ellos se encontraban en una situación de insolvencia. Al ocurrir la devaluación, la situación de estos bancos se vuelve totalmente insostenible.

En Japón, la supervisión y las auditorías no se ajustaron a la rapidez de la desregulación y de la expansión del mercado de créditos (actividades más riesgosas de los bancos fueron poco supervisadas). La efectividad de las auditorías externas era muy limitada debido a que eran consideradas sólo como una formalidad. Desde el inicio de la crisis en 1990, se ha acentuado la desconfianza general sobre los resultados que arrojan estas auditorías, lo que indujo a reformar el esquema de supervisión en 1998.

Además en Indonesia y Japón, las autoridades de supervisión no tenían facultades claras de intervención y suspensión de entidades financieras insolventes. En Malasia, ocurre lo contrario, ya que la ley de Bancos e Instituciones Financieras le otorga la supervisión de las entidades de crédito al Banco Central, quien además tiene amplios poderes para intervenir y recapitalizar a las instituciones financieras ${ }^{12}$.

Las distorsiones a la toma de decisiones de los bancos se acentúan ante la inexistencia de un seguro sobre depósitos explícito y bien estructurado, lo cual ocurre en todos los países con la excepción de Japón. No existe un esquema de seguro explícito para los depósitos, sólo garantías gubernamentales implícitas. Al estallar la crisis los gobiernos se ven forzados a anunciar una garantía al 100\% sobre los depósitos. En Corea, la ausencia de un seguro sobre depósitos explícito provocó incertidumbre entre los depositantes al inicio de la crisis. En Indonesia, para contrarrestar las corridas bancarias, en enero de 1998 el gobierno anuncia que los depósitos serán garantizados al $100 \%{ }^{13}$. A principios de 1998 , Japón también se ve en la necesidad de ampliar la cobertura del seguro de depósitos al 100\% hasta el año 2001 (la

\footnotetext{
${ }^{12}$ Sin embargo, cabe destacar que las supervisiones in-situ no son suficientemente regulares en Malasia.

${ }^{13}$ En Malasia tampoco existía un esquema explícito de seguro sobre depósitos, y en Tailandia los depósitos se garantizan al $100 \%$ desde antes de la crisis.
} 
cobertura del seguro de depósitos original era de 10 millones de yenes por depositante). El esquema de garantías gubernamentales a los depositantes multiplicaron el riesgo moral y la toma indebida de riesgos por parte de los bancos. Esquemas de seguros de depósitos adecuadamente capitalizados y con primas ajustadas a los riesgos asumidos por los bancos por parte de entidades nacionales o extranjeras independientes habrían fortalecido la supervisión y evitado buena parte de los excesos.

\subsubsection{Regulación}

Dentro de la regulación cabe distinguir entre la regulación concerniente a las operaciones de los bancos y la referente a la contabilidad. Por lo general, las reglas de clasificación de créditos, de aprovisionamiento de créditos malos, y de publicación y divulgación de información eran inadecuadas. Para la mayoría de los países analizados, estas reglas no se adecuaban a los estándares internacionales. Las reglas de contabilidad también eran inadecuadas ya que no permitían conocer la situación real de la institución. Lo anterior dificulta la vigilancia de los bancos por parte del mercado y de la autoridad. Los países en los que estos problemas eran particularmente graves son Indonesia, Japón y Tailandia. Una excepción es Malasia, país en el que a raíz de la crisis bancaria de mediados de los ochenta (1985-1988), la supervisión y la regulación fueron significativamente mejorados, por lo que sus sistemas de regulación y supervisión eran más sólidos que los del resto de los países de la región ${ }^{14}$. Ejemplos concretos de mala regulación y prácticas contables inadecuadas son lo siguientes:

En Corea, los bancos asumieron en sus operaciones fuera de balance una alta exposición a derivados en monedas extranjeras ${ }^{15}$. La autoridad no obligaba a los bancos a exhibir la totalidad de sus operaciones fuera de balance, por lo que dichas obligaciones en dólares no fueron reportadas.

En Indonesia, la regulación y la supervisión del sistema financiero era insuficiente. En particular destaca un sistema inadecuado para la calificación de créditos que impide conocer la situación real de las instituciones. Por otra parte, las reglas contables y de aprovisionamiento de cartera no se adecuaron al desarrollo del sistema bancario por lo que no fueron útiles como un mecanismo de alerta temprana.

En Japón, la regulación sobre la divulgación de información de las operaciones de los bancos era inadecuada. No se exigió a los bancos que hicieran pública la información sobre su cartera vencida sino hasta 1993. Además, la definición de cartera vencida era más laxa que la definición internacional (180 días de vencido el pago en vez de 90 días, situación que se corrige en 1998). También era inadecuada la regulación de la información que los bancos debían hacer disponible sobre la administración de riesgos y sobre el valor de mercado de sus activos. Los principios contables no se adaptaron al cambio económico. Mientras que la valuación de los activos financieros a costo de adquisición era una práctica contable conservadora cuando los precios de los mismos subían, una vez que se rompió la burbuja esta

\footnotetext{
${ }^{14}$ En Malasia, en 1989, se aprueba la ley de "Bancos e Instituciones Financieras", gracias a la cual las reglas de contabilidad se acercan a los estándares internacionales de mejores prácticas bancarias. Los estándares de capitalización, la diversificación de riesgos y las reglas para prestamos relacionados son similares a los estándares internacionales. Sin embargo, los criterios de clasificación y aprovisionamiento de riesgos todavía no alcanzan a los estándares internacionales.

${ }^{15}$ En particular, los bancos buscaron aumentar su rentabilidad al asumir riesgos cambiarios de Indonesia (venta de dólares a un tipo de cambio predeterminado en rupias). Al ocurrir la devaluación de diciembre en Indonesia los bancos coreanos aumentaron su demanda por dólares para hacer frente a los márgenes de operaciones en derivados.
} 
práctica contable fue un instrumento para disfrazar pérdidas no realizadas. No existía un sistema regulatorio de acción correctiva temprana que permitiera a las autoridades forzar acciones adecuadas en los bancos.

Otra carencia de la regulación es la falta de una ley de quiebras adecuada que permita la pronta adjudicación de los bienes otorgados como garantía y que permita la reestructuración eficiente de empresas en problemas. Una ley de quiebras deficiente tiene el efecto de propiciar el incumplimiento por parte de los deudores de sus obligaciones, ya que no se les puede obligar a cumplir con los contratos de crédito. Si las garantías que otorgan los deudores como colateral de su crédito no son cobrables, ya que no hay vías legales propicias para que los bancos se adjudiquen esas garantías, entonces se complica y alarga el proceso de la venta de cartera vencida por parte de los bancos o por parte de la agencia encargada de vender los activos bancarios adquiridos a través de esquemas de compra de cartera. Esto incrementa el costo y los plazos para la resolución de las crisis financieras.

La ley de quiebras debe contemplar los mecanismos para la pronta y eficiente reestructuración de empresas en quiebra. Esto es necesario no sólo para el cobro de créditos a cargo de estas empresas, sino también para la venta de la empresa o la liquidación de sus activos en caso de que pasen a manos del gobierno vía la adquisición de su cartera. Las deficiencias en la ley de quiebras son notables en Corea, Japón, Malasia, y Tailandia.

\section{Medidas para Enfrentar la Crisis}

\subsection{Aspectos Generales}

Los países que operaron bajo un régimen cambiario predeterminado antes de la crisis fueron más vulnerables a ataques especulativos contra su moneda; este es el caso de Corea, Indonesia y Tailandia. Cabe destacar que debido a que este régimen cambiario compromete al gobierno a destinar recursos para mantener la paridad del tipo de cambio, los países con este régimen cambiario se han visto forzados a aplicar con mayor velocidad y firmeza apoyos al sistema financiero. Las razones son:

1. El régimen de tipo de cambio predeterminado pareciera haber aumentado la vulnerabilidad de las instituciones financieras al propiciar un mayor endeudamiento externo sin cobertura.

2. La responsabilidad implícita que tienen los gobiernos al otorgar una garantía cambiaria los compromete a aplicar recursos públicos para la resolución de la crisis y eventual rescate de las instituciones financieras.

Contrasta el manejo de la crisis que realizan los países que mantienen un régimen cambiario flexible; como es el caso de Japón y Malasia. Los gobiernos de ambos países han mostrado una mayor resistencia a comprometer recursos públicos para apoyar al sector financiero. Pareciera que estos países han retrasado la implementación de medidas que resuelvan de manera definitiva el problema bancario. Sin embargo, la tardanza en la acción gubernamental podría explicarse por una menor urgencia debido a una problemática menos severa, y a que la responsabilidad de las autoridades en la gestación de la crisis es menor pues no incentivaron un mayor endeudamiento externo a través de su política cambiaria. 
En septiembre de 1998 Malasia revierte su política cambiaria flexible y fija la paridad de su moneda a un tipo de cambio de 3.8 ringgits por dólar, a la vez que impone controles de capital. El argumento principal para esta reversión de política es disminuir la carga de los pagos de la deuda externa privada y aislar al país de los movimientos de corto plazo de los flujos de capital. Las principales medidas de control de capital son: (1) Los recursos que se obtienen por la venta de activos en ringgits podrán convertirse a moneda extranjera sólo después de un año de mantenerlos en moneda local. (2) Las transacciones de activos denominados en ringgits (como acciones) sólo se hará en las instituciones autorizadas. (3) Las importaciones y exportaciones deberán liquidarse en moneda extranjera (para limitar el uso extraterritorial del ringgit). (4) Se restringirá la venta de divisas a los viajeros. (5) Se prohibe a los malayos adquirir activos foráneos que tengan un valor mayor a 10,000 ringgits.

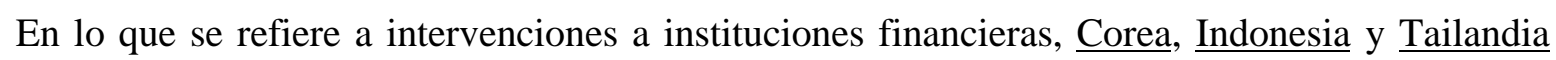
han cerrado e intervenido a un mayor número de entidades y con mayor velocidad que Japón y Malasia. Esto se debe a que enfrentan una crisis de mayor profundidad que ha deteriorado en un mayor grado a las instituciones financieras. Debido a un mayor margen de acción y una mayor resistencia al uso de fondos públicos, los gobiernos de Japón y de Malasia han preferido que estas instituciones en problemas se fusionen con instituciones sanas en lugar de suspenderlas o intervenirlas y permitir, de manera temporal, la operación de bancos con baja capitalización.

En lo que a política fiscal se refiere, al estallar la crisis Corea, y Malasia, que tenían una posición fiscal holgada, adoptan una política fiscal expansiva. El viraje de política se efectúa con el propósito de estimular el crecimiento de la economía y de suavizar el impacto recesivo de la crisis, distribuyendo los costos a través del tiempo. Adicionalmente, Corea relaja su política monetaria. Indonesia y Tailandia, en cambio, adoptan una política fiscal contraccionista en un inicio, aumentando el superávit fiscal; sin embargo, es previsible que el gobierno de Indonesia revierta esta política debido a la profunda depresión e inestabilidad social que enfrenta (ver cuadro 2). Por la severidad de la crisis Tailandia ya ha revertido sus políticas contraccionistas por políticas expansivas. Contrasta Japón que ha seguido una política errática en los noventa. La restricción fiscal implementada a principios de 1997 es probablemente uno de los principales factores del estallido de la crisis en Asia. Como consecuencia de esta alza en los impuestos y una demanda privada débil, el PIB de Japón tuvo una caída del $2 \%$ en vez del aumento de $4 \%$ pronosticado por el FMI. Este grave error de pronóstico de 6 puntos porcentuales redujo fuertemente la demanda por los productos de otras economías asiáticas y contribuyó a la reducción en los flujos de capital hacia estas economías. 


\section{Cuadro 2 \\ Política Fiscal y Monetaria Adoptada a Partir de la Crisis de 1997}

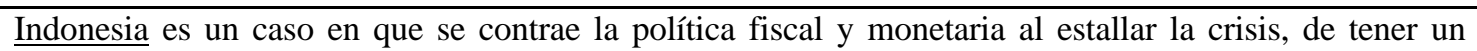
balance físcal en 1996, se estima que en 1997 se alcanzó un superávit fiscal de $2 \%$ del PIB, con todo y la caída del PIB durante el año, mientras que la tasa de fondeo alcanzó un nivel de $81 \%$ al inicio de la crisis.

Tailandia condujo inicialmente una política monetaria restrictiva, la tasa de fondeo pasa de $10 \%$ a mediados de 1997 a niveles de $25 \%$ a principios de 1998. Sin embargo, la severidad de la crisis ha hecho que las autoridades relajen su política monetaria reduciendo dicha tasa de fondeo a un nivel del 6\% en octubre de 1998. Adicionalmente, ha renunciado a su compromiso de conducir una política fiscal contraccionista y ha permitido que déficit fiscal aumente a un nivel de $3 \%$ del PIB (más $1.5 \%$ $2.0 \%$ por el pago de intereses del rescate bancario).

Contrasta la política fiscal de Corea, pues con el fin de suavizar el proceso de ajuste las autoridades intentan distribuir la carga fiscal en varios periodos; se proyecta un déficit fiscal de $1.2 \%$ del PIB para 1998 en comparación con una situación fiscal equilibrada en 1997. Adicionalmente, el Banco Central disminuye la tasa de descuento de $5.0 \%$ a $3.0 \%$ con el fin de impulsar el otorgamiento de crédito.

Malasia, a partir de enero de 1998, conduce una política monetaria restrictiva; la tasa de interés interbancaria aumentó de $8 \%$ a finales de 1997 a 12\% en marzo de 1998. Al mismo tiempo, el Banco Central ha provisto liquidez al sistema financiero reduciendo los requerimientos de reserva de los bancos comerciales de $13.5 \%$ a $10 \%$ en febrero de 1998, y subsecuentemente a $8 \%$ en julio. Por otra parte, las autoridades han adoptado una política fiscal expansiva; el balance del gobierno pasó de un superávit de $2.6 \%$ del PIB en 1997 a un $0.5 \%$ proyectado para 1998.

En cambio, Japón ha seguido una política monetaria expansiva; a partir de 1991 el Banco Central ha reducido paulatinamente la tasa de descuento de un nivel de $6 \%$ hasta su nivel actual que representan un mínimo histórico de sólo $0.25 \%$. En contraste con la política monetaria, durante los años 90 el manejo de la política fiscal ha sido errático. Durante de 1995 hasta principios de 1997 la política fiscal adoptada fue fuertemente expansiva. Los estímulos fiscales en términos de mayor gasto y menores impuestos fueron del orden del $3 \%$ del PIB; este relajamiento complementó a la política monetaria ocasionando un crecimiento superior al 3\% del PIB. Esta situación se revirtió en abril de 1997, cuando para reducir el déficit el gobierno aumentó el impuesto al consumo de 3\% al 5\% y eliminó la reducción temporal al impuesto sobre la renta. Esta política tuvo un efecto severo sobre el sector privado y la actividad económica. Durante 1998 se ha adoptado nuevamente una política fiscal expansiva. (Para mayores detalles ver el anexo, Japón cuadro II)

\subsubsection{Prestamista de Última Instancia a Nivel Internacional}

Como respuesta a la severidad de la crisis asiática, las organizaciones financieras internacionales y algunos países desarrollados han otorgado paquetes de asistencia sin precedente para tratar de contener la crisis en Asia. Créditos substanciales por parte del Fondo Monetario Internacional se complementan con asistencia por parte del Banco Mundial, el Banco de Desarrollo Asiático y algunos países industrializados.

Los países que mantuvieron un régimen cambiario semi-fijo (Corea, Indonesia y Tailandia) requirieron del apoyo internacional para solventar sus compromisos con el exterior. En agosto de 1997, Tailandia obtiene un paquete de ayuda internacional de emergencia por $17.1 \mathrm{mil}$ millones de dólares. El apoyo a Indonesia tarda un poco más de tiempo, pues la percepción negativa que existía sobre su gobierno dificultó la estructuración del paquete de apoyo; el 
gobierno logra en octubre de 1997 que el Fondo Monetario Internacional, el Banco Mundial y otros gobiernos comprometieran un paquete de ayuda financiera por 36.6 mil millones de dólares, posteriormente obtiene 10.8 millones de dólares adicionales. El último de los países en obtener apoyo internacional fue Corea que el 4 de diciembre de 1997 acuerda con el Fondo Monetario Internacional, el Banco Mundial y un grupo de países industrializados un paquete de ayuda financiera por 58.2 mil millones de dólares (ver cuadro 3 ).

\section{Cuadro 3}

Paquete de Ayuda Internacional (en miles de millones de dólares)

\begin{tabular}{|l|c|c|c|c|}
\hline & $\begin{array}{c}\text { Fondo } \\
\text { Monetario } \\
\text { Internacional }\end{array}$ & $\begin{array}{c}\text { Banco Mundial y Banco } \\
\text { de Desarrollo de Asia }\end{array}$ & Asistencia Bilateral & Total \\
\hline$\underline{\text { Indonesia }}$ & 16.1 & 8.0 & 23.2 & 47.4 \\
\hline$\underline{\text { Corea }}$ & 20.9 & 14.0 & 23.3 & 58.2 \\
\hline$\underline{\text { Tailandia }}$ & 3.9 & 2.7 & 10.5 & 17.1 \\
\hline Total & 34.7 & 24.7 & 52.5 & 111.9 \\
\hline
\end{tabular}

Fuente: Fondo Monetario Internacional.

\subsubsection{Intervención de Instituciones Financieras}

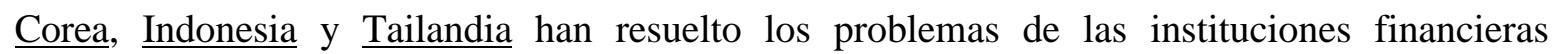
mediante la suspensión de operaciones y/o la intervención gerencial. Esto puede deberse tanto al mayor deterioro e incertidumbre que enfrentan las instituciones de dichos países como a la falta de inversionistas dispuestos a adquirir activos bancarios a precios razonables. Japón y Malasia han tratado de resolver los problemas de sus instituciones mediante soluciones privadas que no involucren recursos públicos, como puede ser la fusión o la adquisición privada de cartera crediticia (ver detalles en cuadro 4). 


\section{Cuadro 4 \\ Intervención a las Instituciones Financieras}

En Japón, de diciembre de 1994 a noviembre de 1996, se fusionaron 13 instituciones financieras, en 7 de éstas el Banco Central de Japón apoyó financieramente la operación. Sin embargo, las quiebras en noviembre de 1997 del Banco Hokkaido y de Valores Yamaichi, registran disparidades entre el capital reportado unos meses antes y el capital verdadero por más de 500 mil y 260 mil millones de yenes respectivamente. Estos bancos se someterán al esquema del banco puente que se explica en el anexo, cuadro III de Japón.

Corea ha atacado el problema de insolvencia con gran decisión. En diciembre de 1997, cierran 14 bancos mercantiles (estos bancos no aceptan depósitos de personas físicas). Esta situación provocó que se acelerara el retiro de depósitos del sistema bancario y que los bancos disminuyeran el crédito otorgado, cancelando incluso líneas de crédito previamente autorizadas. En febrero de 1998 se suspenden las operaciones de otro banco mercantil y se realiza una intervención a dos de los principales bancos comerciales (Banco Primero de Corea y Banco de Seúl) que se ha programado reprivatizar en noviembre de 1998 .

En Indonesia durante diciembre de 1997 la autoridad financiera ordena el cierre de 16 bancos con el propósito de enviar la señal de que no se rescataría a instituciones insolventes. En febrero de 1998 se creó la Agencia de Reestructuración Bancaria de Indonesia (IBRA). Esta agencia colocó inmediatamente a 54 bancos bajo una vigilancia especial; en abril de 1998, suspendió las operaciones de 7 de estos bancos e intervino gerencialmente a 8. Las intervenciones se efectuaron con un mandato discrecional que no define procedimiento o tiempo alguno de reprivatización. Por otra parte, debido a la falta de personal en IBRA, la administración de 7 de los 8 bancos intervenidos la conducen bancos estatales hasta llegar a otro arreglo. En septiembre de 1998 el gobierno recibe de los bancos intervenidos acciones que le dan el control de más de 100 compañías como pago por los préstamos de emergencia que les extendió.

Tailandia inició la implementación de medidas correctivas en diciembre de 1997, la primera acción fue intervenir a 48 compañías financieras. Posteriormente a principios de 1998 se intervinieron cuatro bancos comerciales, y en mayo de 1998 se intervinieron otras 7 compañías financieras. La recapitalización de las 7 compañías financieras intervenidas en mayo se efectuó con una emisión de capital que suscribe el Fondo de Desarrollo de las Instituciones Financieras.

En Malasia no se han suspendido las operaciones de ninguna institución financiera y se han intervenido únicamente a un banco comercial y a dos compañías financieras. La respuesta ante la problemática bancaria ha sido a través de importantes inyecciones de liquidez del Banco Central al sistema financiero y del apoyo a las fusiones. En enero de 1998, los depósitos del Banco Central en instituciones financieras representaba el 13\% del PIB. Es importante notar que estas inyecciones se han dado indiscriminadamente a instituciones insolventes como a instituciones con problemas de liquidez. Hasta marzo de 1998, se han fusionado 16 compañías financieras con otras 6 de mayor tamaño y con 2 bancos. El apoyo del Banco Central consiste en otorgar una garantía de un año contra el deterioro de los activos de las instituciones recién adquiridas. La garantía se aplica sólo después de una extensa auditoría sobre las compañías financieras adquiridas. 


\subsubsection{Seguro de Depósitos}

Corea, Indonesia y Malasia no tenían un seguro de depósitos explícito. Japón tenía un seguro de depósitos con una cobertura limitada y Tailandia desde antes de la crisis tiene una garantía explícita que cubría el $100 \%$ de los depósitos. A raíz de la crisis, todos los países se han visto forzados a garantizar la totalidad de los depósitos para evitar corridas bancarias. En Indonesia, el gobierno ofreció una garantía limitada hasta por 5,000 dólares a los depositantes de los primeros bancos que suspendieron sus operaciones. Esta medida provocó que los depositantes pierdan la confianza en el sistema bancario y que ocurra un retiro masivo de depósitos. Ante esta situación el gobierno anunció una garantía por el $100 \%$ de los depósitos. Aún así, la confianza no se recuperó inmediatamente, razón por la que las corridas bancarias han sido recurrentes, quizá por problemas de información o por la inestabilidad política y social que se vive en este país.

\subsubsection{Relajamiento de la Regulación Bancaria al Estallar la Crisis}

Frecuentemente, las autoridades financieras mantienen operando a algunas instituciones financieras insolventes mediante el relajamiento de la regulación bancaria. El argumento que dan para no cumplir adecuadamente con su función se basa típicamente en la idea de que el reconocimiento de la quiebra manda señales equivocadas a los mercados, propiciándose corridas bancarias y la quiebra de instituciones solventes. La eficacia de la regulación se pierde debido a que de antemano los agentes económicos anticipan que está no va a ser aplicada en los momentos claves. En Japón e Indonesia la regulación bancaria se relajó inicialmente, sin embargo las autoridades de Corea han insistido en que los bancos en operación cumplan de manera estricta con los requerimientos de capitalización. En Malasia inicialmente se fortalece el marco regulatorio para volver a relajarlo posteriormente con el fin de aligerar las restricciones de capital que enfrentan los bancos (ver cuadro 5).

\section{Cuadro 5}

\section{Relajamiento a la Regulación Bancaria}

En agosto de 1992 Japón permitió que los bancos valuaran las tenencias accionarias a su valor en libros en lugar de que se registrasen a valor de mercado; evitando que los bancos tuvieran que reconocer pérdidas como resultado de la caída en el precio de las acciones. Sin embargo, a raíz de las reformas denominadas "Big Bang” de 1996 (ver cuadro V de Japón en el Anexo), a finales de 1999 la valuación de estas tenencias accionarias se deberá hacer a precio de mercado, lo que implica que los bancos tendrán que asumir las pérdidas o aumentar sus provisiones para cubrir la diferencia. Otra medida que adoptó el gobierno de Japón es la de establecer requisitos de capitalización duales. Los bancos con operaciones internacionales (los más grandes) tienen que satisfacer la capitalización del $8 \%$ que marca el BIS, mientras que los bancos con operaciones nacionales sólo tienen que mantener un nivel de capitalización del $4 \%$.

En Indonesia, el ministerio de finanzas ha ordenado reducir de manera temporal los requerimientos de capitalización en los 70 bancos que no se han intervenido. Los requerimientos se relajan de la siguiente manera: en 1998 de 8 a 4\%, en 1999 de 10 a 8\%, y en el año 2000 de 12 a $10 \%$.

En Malasia, el Banco Central relaja en septiembre de 1998 la regulación bancaria después de haber tomado medidas iniciales tendientes a fortalecerla (ver cuadro 8). Las medidas de relajamiento son: (1) Se amplía el periodo de clasificación de créditos vencidos de 3 a 6 meses. (2) Disminuye el periodo de pagos continuos necesarios para reclasificar un crédito vencido a la categoría de vigente de 12 a 6 meses. (3) Se elimina la obligación a los bancos de provisionar automáticamente el $20 \%$ de los créditos vencidos. (4) Aumenta el límite a los créditos que se pueden otorgar para la compra de acciones o fideicomisos de bancos comerciales y compañías financieras de $15 \%$ a $20 \%$. 


\subsection{Medidas de Saneamiento}

En los cinco países de Asia bajo estudio se ha contemplado la adquisición de cartera bancaria con el fin de apoyar el saneamiento de la banca. Sin embargo, es común que la implementación de estos programas sea lenta debido a que no existen las instituciones ni los procedimientos para llevarlos a cabo. Corea es el único país de los cinco cuyo gobierno ha adquirido cartera de los bancos. En Japón, sólo ha habido un esquema privado de traspaso de cartera mediante una cooperativa de instituciones financieras. Los otros países están en proceso de adecuar el marco institucional para poder utilizar recursos públicos para la adquisición de cartera (ver detalles en cuadro 6).

Por otro lado, el proceso de reprivatización de los activos de las instituciones suspendidas e intervenidas ha sido lento y limitado, ya que también hay una insuficiencia de instituciones y procedimientos que permitan la disposición de dichos activos. Contrasta el caso de Corea, que se ha comprometido a vender los principales bancos intervenidos en un periodo menor a un año.

\section{Cuadro 6 \\ Programas de Adquisición de Cartera}

Entre diciembre de 1997 y febrero de 1998 en Corea, la Compañía de Administración de Activos (CAMCO) adquirió 35\% de la cartera vencida de los bancos, monto equivalente a 3.8\% del PIB. De acuerdo a una valuación de los activos, CAMCO pagó por éstos un precio promedio de 50\% de su valor contable. Sin embargo, el programa de adquisición de cartera se interrumpió desde febrero de 1998 debido a la falta de criterios de adquisición. Aún no se definen estos criterios.

En Indonesia, el Ministro de Finanzas ha anunciado la adquisición de cartera vencida; sin embargo, hasta la fecha no se ha implementado dicho programa que depende de la creación de la Unidad de Administración de Activos (AMU) que no se ha materializado. Por esto no ha sido posible que la Agencia de Reestructuración Bancaria de Indonesia (IBRA) adquiera activos ni que tampoco venda los activos de los bancos que han suspendido operaciones. El retraso en la constitución de la AMU el gobierno ha impedido que se recapitalice a los bancos en problemas y la venta de los activos correspondientes a los bancos intervenidos.

En Japón, los programas de adquisición de cartera han sido privados. En enero de 1993, 162 instituciones financieras crearon la Compañía Cooperativa de Compra de Créditos, que ellas mismas capitalizaron con aproximadamente 700 millones de dólares, con el fin de resolver de manera privada los problemas de los créditos malos. Esta compañía tuvo a su cargo la función de compra de cartera vencida colateralizada con bienes raíces, y la venta de los créditos o en su caso la del colateral.

En Malasia no ha habido ninguna compra de cartera hasta la fecha pues se está en proceso de crear las instituciones que puedan efectuar dichas adquisiciones. En julio de 1998, el Parlamento aprobó una ley para la creación de la Compañía de Administración de Activos (AMC) que tendrá la encomienda de adquirir y vender cartera vencida de instituciones financieras en problemas. El capital inicial de esta entidad será otorgado por el Ministerio de Finanzas, pero se planea que posteriormente su financiamiento provenga de capital privado. La AMC estará dirigida por un consejo de administración que consiste de nueve directores, de los cuales 7 son del sector privado y sólo 2 del sector público.

En Tailandia no se ha efectuado un programa de adquisición de cartera. Sin embargo, las autoridades tienen la intención de subastar los activos de los bancos que se han intervenido y utilizar recursos públicos para tal efecto. En dichas subastas pueden participar el RAB, que es un banco público, y la Corporación de Administración de Activos (AMC). La AMC es una institución de reciente creación que se estableció en octubre de 1997 con capital del Ministerio de Finanzas con el mandato de manejar y disponer de los activos en poder del gobierno. La intención de las autoridades es que el RAB compre los activos de mejor calidad y que la AMC adquiera los de peor calidad, de manera que la AMC actúe como un "comprador de última instancia". 
Japón y Malasia han utilizado de manera preponderante esquemas de capitalización privados con un uso limitado de recursos públicos. Corea, Indonesia y Tailandia han comprometido una mayor proporción de recursos públicos para la resolución de la crisis y se encuentran en proceso de adecuar su marco institucional para poder utilizar dichos recursos de manera eficaz.

En Indonesia las autoridades consideraron que una medida indispensable para lograr una adecuada capitalización bancaria era la reestructuración de la deuda privada. Sin embargo, esta medida no se ha implementado debido a la inestabilidad cambiaria y las elevadas tasas de interés que sólo recientemente han descendido. Lo anterior forzó a varias empresas a incumplir en el pago de sus obligaciones tanto domésticas como externas.

\section{Cuadro 7}

\section{Capitalización Bancaria}

En Japón con el paquete de leyes de octubre de 1998 se crea el Comité de Revitalización Financiera el cual podrá optar entre liquidar los bancos fallidos, controlarlos completa o parcialmente con la compra de amplios paquetes de acciones o transferirlos al esquema de "bancos puente". Se prevé que el gobierno nacionalice temporalmente a los bancos insolventes de los que adquiera acciones. Se establece que aquellos bancos cuya razón de capital caiga por debajo del $2 \%$ podrán ser nacionalizados. Asimismo, el paquete de leyes de octubre de 1998, permite al gobierno inyectar recursos a bancos con niveles de capitalización superiores al 8\%. Los fondos con los que el gobierno cuenta para la nacionalización, el esquema de bancos puente y la recapitalización de los bancos ascienden a un total de 43 billones de yenes, es decir millones de millones.

El esquema de bancos puente, que entró en vigor en septiembre de 1998, tiene el objetivo de administrar la cartera y en su caso capitalizar a los bancos insolventes. Dicho esquema se va a implementar en dos fases. El Seguro de Depósitos consolidará a todos los bancos en una empresa controladora, Compañía de Revitalización Financiera Heisei (HFRC), la cual organizará a los bancos puente como subsidiarias. En la primera fase, al momento que quiebre un banco, la Agencia de Supervisión Financiera asignará un administrador para que intervenga el banco con el mandato de fusionar el banco quebrado con un banco privado. Si esto no es posible deberá transferirlo a un banco puente para que éste asuma su administración. Los bancos puente son temporales y deberán transferir los pasivos y activos de los bancos quebrados a bancos privados en un periodo máximo de 2 años, que en circunstancias extraordinarias puede extenderse por otros tres años. Asimismo, podrá otorgar créditos a los deudores "buenos" del banco quebrado, previa autorización de un comité examinador de créditos organizado por el HFRC. La segunda fase, que consiste en la nacionalización del banco, ocurre si no se puede vender el banco quebrado.

En Corea la Compañía de Administración de Activos (CAMCO) realizó hasta febrero de 1998 inyecciones de capital a los bancos por montos equivalentes a $0.7 \%$ del PIB y además ha adquirido deuda subordinada por un monto equivalente al $1 \%$ del PIB; se estima que una vez que se reanuden las inyecciones de capital éstas pueden llegar a ser del orden del $11 \%$ del PIB.

En Tailandia el gobierno ha solicitado a las 35 compañías financieras que no han suspendido operaciones que sometan planes de recapitalización a la Agencia de Reestructuración Financiera. Por otra parte, las compañías financieras intervenidas serán consolidadas en una compañía financiera pública que será capitalizada mediante la emisión de acciones que va a suscribir el Fondo de Desarrollo de las Instituciones Financieras.

En Indonesia no ha habido un programa de recapitalización bancaria que utilice recursos públicos. Sin embargo, se ha pensado en un mecanismo de apoyo a los deudores que contribuya a disminuir la cartera vencida de las instituciones. Con este fin el 3 de agosto de 1998, la Agencia de Reestructuración de Deuda (INDRA) inicia operaciones con el mandato de otorgar una garantía contra el riesgo cambiario de la deuda externa de las empresas que decidan participar en el esquema y se inscriban durante el periodo comprendido entre el 8 de agosto de 1998 y el 30 de junio de 1999. El esquema de INDRA contempla subsidios limitados a las empresas con deudas en moneda extranjera, ya que no habrá un tipo de cambio preferencial para el pago de dichas deudas, y además las empresas pagarán una tasa de interés real de $5.5 \%$ en rupias o Libor más 300 puntos base en dólares. Los deudores que recurran a INDRA tienen la opción de reestructurar su deuda en rupias si esta se aprecia en los primeros dos años.

En Malasia no se han comprometido recursos públicos para recapitalizar a las instituciones financieras; el gobierno prefiere la fusión de instituciones con una capitalización privada. Durante la primera mitad de 1998, se han fusionado 39 compañías financieras en 8. De éstas, 7 ya cumplen con los nuevos requerimientos mínimos de capital de 600 millones de ringgits. 


\subsection{Acciones para resolver la crisis: El caso de Japón}

Desde principios de 1998, debido a la agudización de la crisis financiera, Japón ha venido adoptando un gran número de medidas de emergencia económica relacionadas con el sistema financiero. El creciente deterioro de la salud de las instituciones financieras y el reconocimiento de la importancia que tiene el sistema financiero para el desarrollo económico del país, la profundización financiera es muy elevada (los 19 bancos más grandes han otorgado créditos por un monto equivalente al $74 \%$ del PIB), se han conjuntado con un cambio de visión fundamental sobre el papel que debe jugar el gobierno para resolver la crisis. En 1998 se acepta por primera vez, después de 8 años de estancamiento y creciente crisis financiera, la necesidad de inyectar grandes cantidades de recursos públicos a las instituciones financieras con el objeto de sanearlas.

\subsubsection{Reforma y Capitalización del Seguro de Depósitos}

Han existido varios esfuerzos por reformar al Seguro de Depósitos. En 1996 se elimina el límite del que puede disponer la Compañía de Seguro de Depósitos para liquidar un banco. También se aumenta 7 veces la prima pagada por los bancos y se autoriza a la Compañía de Seguro de Depósitos contraer préstamos respaldados por el gobierno para resolver la quiebra de cooperativas de crédito. A principios de 1998 se vuelve a reformar la Ley del Seguro de Depósitos. Dicha reforma fortalece la estructura financiera de la Compañía de Seguro de Depósitos. Se recapitaliza el Seguro con 17 billones de yenes ( 7 billones de yenes en Bonos del Gobierno y 10 billones en forma de préstamos del banco central garantizados por el gobierno) para garantizar los depósitos de instituciones financieras insolventes. Se amplía la cobertura del seguro de depósitos al 100\% hasta el año 2001 (la cobertura del seguro de depósitos original era de 10 millones de yenes por depositante). Se ignora cuál será la cobertura del seguro a partir del año 2002.

Simultáneamente con la ley que recapitaliza al Seguro de Depósitos, a principios de 1998 se promulga la Ley de Medidas de Emergencia para Estabilizar el Sistema Financiero, por la cual se preveía la inyección de hasta 13 billones de yenes a instituciones en problemas a través de la compra de acciones preferenciales u obligaciones subordinadas. La Compañía de Seguro de Depósitos administraría estos recursos públicos a través de una cuenta especialmente creada por el gobierno para tal efecto en el Seguro. Se estableció un Comité encargado de supervisar las operaciones de capitalización y que determinaría los criterios que deben cumplir las instituciones que solicitan apoyo. Este esquema de apoyo ha recibido fuertes críticas, pues el gobierno ha estado tratando de usarlo para inyectar recursos a todo tipo de bancos, no sólo los bancos que se ha establecido que tienen problemas. Existe una fuerte oposición de bancos "sanos" a recibir aportaciones de capital pues ello diluye los ingresos de los accionistas, puede dar una imagen equivocada de la salud del banco y además, por ley, las instituciones tienen que someter a las autoridades un plan que asegure su solvencia con medidas de racionalización, de mejoras y otras que aseguren la salud de sus operaciones.

El gobierno de Japón ha dado dos justificaciones para inyectar recursos públicos incluso a bancos "sanos". Una justificación inicial fue el tratar de evitar que el público y el mercado discriminaran entre bancos. Posteriormente, señaló que es necesario elevar la capitalización de los bancos al $12 \%$ para evitar la contracción de crédito (credit crunch). Ambos argumentos son criticables, ya que es bueno para el eficiente funcionamiento de los mercados el que el público 
pueda distinguir entre bancos buenos y malos, pues de otra manera los bancos buenos subsidian a los malos, lo que induce a todos los bancos a una toma de riesgos excesiva. Además, con el esquema de seguro de depósito establecido en Japón, la probabilidad de que ocurran corridas bancarias es insignificante. El que el mercado pueda distinguir entre bancos buenos y malos no tiene un costo en términos de mayor riesgo sistémico. En relación con la idea de elevar al 12\% la capitalización de los bancos, existe la opinión entre algunos analistas que en vez de resolver el "crunch" de crédito lo puede acentuar. En todo caso cabe enfatizar que el utilizar recursos públicos para subsidiar a los bancos por encima de lo mínimo requerido legalmente puede generar diversos problemas a futuro como son el que se cuestione la conveniencia de dichas aportaciones y que se siente un precedente de rescate gubernamental a la banca que se perciba como excesivamente generoso.

\subsubsection{Aumento de los recursos públicos para combatir la crisis financiera}

El poder legislativo aprobó en octubre de 1998 en dos partes un nuevo paquete de leyes para enfrentar la crisis financiera. La primera parte, aprobada el 12 de octubre, se refiere a la creación de un Comité de Revitalización Financiera (para mayores detalles ver anexo, Japón cuadro III). La segunda, aprobada el 16 de octubre establece recursos adicionales para el saneamiento de las instituciones financieras. Este paquete de leyes deroga buena parte de la Ley de Medidas de Emergencia para Estabilizar el Sistema Financiero promulgada a principios de 1998.

Las leyes aprobadas el 16 de octubre contemplan destinar hasta 18 billones de yenes de recursos públicos a instituciones insolventes. Además, se contempla la posibilidad de que el gobierno inyecte hasta 25 billones de yenes a instituciones débiles pero solventes, posiblemente con niveles de capital superiores al $8 \%$. Para tal efecto, se crean dos nuevas cuentas en el seguro de depósitos (para mayor detalle de las cuentas ver anexo, Japón cuadro III). Estas cuentas cancelan la cuenta especial de hasta por 13 billones de yenes creada en la Ley de Medidas de Emergencia. El efecto neto de esta nueva ley es por tanto aumentar los recursos públicos disponibles para el rescate del sistema financiero en 30 billones de yenes $(6 \%$ del PIB). Si se toma en cuenta que el capital al que puede acceder el Seguro de Depósitos para garantizar los depósitos es de 17 billones de yenes, y este monto no fue modificado por las leyes de octubre, durante 1998 el gobierno japonés habrá comprometido inyectar recursos públicos al sistema financiero hasta por 60 billones de yenes, es decir 12\% del PIB.

El paquete de nuevas leyes permite al gobierno inyectar recursos a bancos con niveles de capitalización superiores al 8\%. El Comité de Revitalización Financiera tiene gran discrecionalidad para decidir a qué bancos inyectar recursos. En tanto no se integre el comité a finales de diciembre será el primer ministro quien decida que bancos califican para recibir estos apoyos. Cabe destacar que desde antes de promulgarse estas nuevas leyes, el gobierno y el banco central han estado presionando a los bancos más grandes para que acepten inyecciones de capital. Esta política parece estar produciendo frutos. A finales de octubre se anunció que los bancos Fuji, Tokai, Daiwa solicitarían fondos públicos al igual que el Banco Industrial. Este último es el primer gran banco que solicitó fondos públicos con el objeto de aumentar su capitalización. 


\subsubsection{Política fiscal expansiva durante 1998}

Durante 1998 el gobierno japonés adoptó una política fiscal cada vez más expansiva debido al continuo deterioro de la economía durante el año, (al principio del año se estimaba un crecimiento del PIB del 1.9\%, actualmente se espera una caída del 1.8\%). De aprobarse por la Dieta el paquete anunciado el 16 de noviembre de 1998, el gobierno habrá comprometido estímulos fiscales por aproximadamente 7.7\% del PIB. Estos estímulos fiscales incluyen el año fiscal de 1998 y el de años fiscales subsecuentes. El estímulo fiscal para el año fiscal 1998 (que corre de abril de 1998 a marzo de 1999) estimamos que sea del orden de 4 puntos porcentuales del PIB. Los 3.7 puntos restantes representan un estímulo fiscal para años subsecuentes.

El presupuesto original para el año fiscal de 1998 incluía un recorte temporal de impuestos por 4 billones de yenes ( $0.8 \%$ del PIB). A este presupuesto se le han adicionado dos paquetes de estímulo adicionales. El primero por 16 billones de yenes (3.2\% del PIB), aprobado el 17 de junio, se ha destinado a aumentar el gasto en obras públicas de la segunda parte del año fiscal. Los analistas han dudado de que el gobierno pueda llevar a cabo el programa toda vez que parte del financiamiento del gasto recae sobre jurisdicciones que tienen una situación fiscal débil. El segundo paquete no fue aprobado en la última sesión ordinaria de la Dieta. No obstante ello, el 16 de noviembre el Primer Ministro anuncia el mayor paquete de estímulo económico de la historia por un monto aproximado de 24 billones de yenes. El cual deberá ser aprobado por la Dieta. El monto de este paquete suplementario se desagrega de la siguiente manera. Alrededor de 17 billones se destinarán a gasto público, créditos y consumo. (8.1 billones en obras de infraestructura social, 5.9 billones de yenes en préstamos para contrarrestar la escasez de créditos, 1.0 billones para otorgar créditos blandos a países del sudeste asiático, 1.0 billones para fomentar la creación de empleo, 0.7 billones en cupones de consumo). Esta parte del paquete pudiera quedar aprobada en una sesión extraordinaria de la Dieta a principios de diciembre. Los 7 billones restantes es el valor presente de los ingresos que dejará de percibir el gobierno al reducir de manera permanente las tasas impositivas a partir del año fiscal de 1999. De aprobarse por la Dieta la reforma fiscal a principio de 1999, la tasa máxima a las personas físicas se reduciría del $65 \%$ al $50 \%$, mientras que la tasa efectiva del impuesto a las empresas se reduciría a un nivel de alrededor del $40 \%$.

\subsubsection{Paquetes de apoyo a los países de Asia}

En octubre de 1998 el gobierno japonés anunció un paquete de ayuda a los países de Asia por 30 mil millones de dólares. En el paquete de estímulo económico por 24 billones de yenes anunciado el 16 de noviembre se contemplan 1.0 billones de yenes en créditos en yenes a países de Asia. Este billón de yenes equivale a aproximadamente 8300 millones de dólares.

Adicionalmente en noviembre de 1998 Japón y Estados Unidos anunciaron un paquete de crédito por 10 mil millones de dólares, de los cuales Estados Unidos aportará la mitad y Japón junto con el Banco Mundial y el Banco Asiático de Desarrollo la mitad restante. De los 5 mil millones que aportará Estados Unidos se canalizarán 1 mil millones a Corea del Sur, y otros tantos a Indonesia y Tailandia. 


\section{Fortalecimiento del Marco Regulatorio y de Supervisión}

Una vez que se adoptan las medidas indispensables para contener la crisis, las autoridades se abocan a la revisión del marco regulatorio y de supervisión. El objetivo que persiguen al fortalecer el marco regulatorio es resolver de manera definitiva la crisis, así como evitar que ésta pueda repetirse. Se busca que el sistema se sujete a una mayor disciplina de mercado y que los bancos administren adecuadamente los riesgos y sean menos vulnerables a cambios en el entorno económico interno y externo que pudieran acelerar el deterioro de la cartera de los bancos y poner en riesgo la salud del sistema financiero en su conjunto. Las crisis muchas veces muestran las carencias y debilidades de los mecanismos de supervisión, por lo que inducen a los gobiernos a fortalecerlos. Para fortalecer la supervisión de mercado es necesario transparentar la operación de los bancos y los riesgos que estos asumen. Es fundamental que la entidad supervisora sea capaz de vigilar y tenga la obligación de sancionar aquellos bancos que no cumplan con la regulación. Por ello resulta necesario proveer a la entidad supervisora de responsabilidades para garantizar que vigile y sancione eficazmente a los bancos.

El proceso de fortalecimiento del marco regulatorio y de la entidad de supervisión es distinto de país a país. Estos procesos de cambio estructural toman tiempo y usualmente se encuentran dentro de la última etapa de resolución de las crisis. Por lo tanto, los avances en estas reformas dependen de que tan avanzado se encuentre el país en el proceso de resolución. Por lo anterior, no es de extrañarse que Japón sea el país que más avances tenga en ese sentido. Esto contrasta con el caso de Indonesia, que es un país que todavía no ha iniciado las reformas estructurales necesarias. La devaluación del baht de Tailandia ocurrió hace poco más de un año, por lo que no es de extrañarse que la mayor parte de las reformas a la regulación y supervisión en Corea,

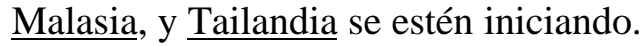

En general, las medidas que se imparten con más rapidez en los países analizados son las de regulación prudencial y las referentes a la obligación de mantener una cartera de crédito diversificada. También, es común que se liberalice la inversión extranjera en el sector bancario con el fin de atraer capital fresco para un sector que comúnmente se encuentra descapitalizado y carente de capital humano adecuado. Además, los países se abocan a otorgar mayores facultades a la entidad supervisora y a adoptar estándares internacionales concernientes a auditorías, clasificación de activos y divulgación de información.

\subsection{Fortalecimiento de la Regulación Prudencial}

La regulación prudencial tiene el objetivo de evitar el deterioro de los activos bancarios. Dado lo anterior, los países analizados comúnmente emiten reglas tendientes a reforzar los requerimientos de capitalización, los estándares contables y los requerimientos de información. En todos los casos, los países emiten esas reglas basándose en los estándares internacionales de mejores prácticas bancarias del Comité de Basilea sobre Principios para una Supervisión Bancaria Efectiva. 


\title{
Cuadro 8 \\ Fortalecimiento del Marco Regulatorio
}

\begin{abstract}
En Japón, se aprueban diversas leyes con el fin de llevar los criterios de valuación y clasificación de activos conforme a los estándares internacionales. A partir de 1998 se modifican los criterios contables en lo que se refiere a la definición de cartera vencida. Se considera como cartera vencida a los 90 días naturales posteriores al vencimiento de los pagos en concordancia con la práctica internacional, en vez de los 180 días establecidos hasta entonces. El gobierno japonés ha declarado recientemente que como parte de su iniciativa de introducir estándares internacionales de contabilidad y de divulgación de información, planea introducir una contabilidad basada en precios de mercado para los instrumentos financieros a partir de marzo del 2001.

En Corea, el Comité de Desincorporación Bancaria se ha comprometido a publicar en agosto de 1998 un nuevo marco regulatorio prudencial que se asemeje a la mejor práctica internacional. Esta regulación incluirá los siguientes puntos: i) deducir de la definición de capital neto a las provisiones, con excepción de aquéllas que se clasifiquen como normales o precautorias, ii) contabilizar las acciones y derivados al precio de mercado, con excepción de aquéllas que cubran activos a su valor histórico, iii) incluir a los fideicomisos con garantía en las operaciones dentro del balance del banco, iv) revisar los procedimientos para la clasificación de créditos, considerando la capacidad de repago y no únicamente el desempeño pasado. Además, se clasificará a los créditos con un vencimiento superior a 90 días como vencidos, v) aumentar los requerimientos de aprovisionamiento.

En Malasia, se aprueban inicialmente una serie de medidas regulatorias tendientes a llevar los aspectos de la regulación bancaria que no estaban en línea con los estándares internacionales: clasificación de créditos como cartera vencida pasa de 6 a 3 meses, aprovisionamiento adecuado de los créditos y mejor vigilancia de los riesgos fuera de balance. El requerimiento de capital sobre activos mínimo de las compañías financieras (actualmente 8\%) aumenta a 9\% para finales de 1998, y a 10\% para finales de 1999. Además, el capital mínimo aumenta de 5 a 600 millones de ringgits. Sin embargo, en septiembre de 1998 el Banco Central se retracta y relaja de nuevo algunas de las nuevas reglas, como la clasificación de créditos en cartera vencida, aprovisionamiento y otras medidas tendientes a aligerar las restricciones de capital sobre los bancos (ver cuadro5).

En Tailandia, el gobierno anunció un plan para establecer reglas de contabilidad y de regulación según el estándar internacional de mejores practicas bancarias. Estas reglas se emitirán de manera gradual de aquí al año 2000 y se refieren principalmente a los niveles de capitalización y a la adecuada clasificación y aprovisionamiento de los créditos. Desde julio de 1998, se considera como cartera vencida cualquier crédito con pagos atrasados de por lo menos 3 meses, en vez de 6 meses. Las primeras reglas sobre valuación de colateral y de deudas reestructuradas se implementaron en marzo de 1998.
\end{abstract}

Es importante distinguir entre regulación prudencial, que es una regulación más bien pasiva, y regulación activa. La regulación pasiva tiene el fin de evitar el deterioro de los activos, mientras que la regulación activa permite a la autoridad de supervisión tomar acciones correctivas con el fin de evitar la baja capitalización de las entidades de crédito. Hasta la fecha,

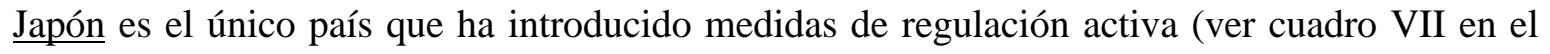
anexo).

\subsection{Diversificación de la Cartera}

Como se vio en la segunda sección, la excesiva concentración de créditos en el sector de bienes raíces y de acciones bursátiles (por parte de bancos comerciales y de compañías financieras) en Japón, Malasia y Tailandia fue un factor significativo que contribuyó al deterioro de los activos de las instituciones financieras. Al estallar la crisis y producirse una deflación en el precio de los activos, los créditos se vuelven incobrables ya que el colateral pierde su valor. En el caso 
de la excesiva concentración de créditos en un solo cliente, como en Corea, sucede algo similar. Al ligar la salud del banco al desarrollo de un solo sector o cliente aumenta la probabilidad de que la cartera se deteriore aún más. Dado lo anterior, países como Corea y Malasia se enfocaron a reformar la regulación concerniente a la exposición al riesgo; quedando pendientes las reformas en ese sentido para Japón y Tailandia.

En Corea, el gobierno se ha comprometido a introducir en noviembre de 1998 reglas que impongan límites a la exposición al riesgo cambiario en los bancos, así como a las subsidiarias de los bancos coreanos en el exterior. Adicionalmente, estudian la modalidad y cronograma para imponer límites a los créditos relacionados.

En Malasia, se reducen los límites a los créditos relacionados; el límite de crédito a un solo cliente se reduce de 30 a $25 \%$ del total de créditos que otorgue una institución financiera. Además, en abril de 1998, el banco central establece límites al otorgamiento de nuevos créditos por sector: $20 \%$ para bienes y raíces y $15 \%$ para la compra de acciones. Sin embargo, un mes después, el banco central prohibe por completo el otorgamiento de nuevos créditos al sector bienes raíces.

\subsection{Desregulación Financiera}

Las deficiencias de un marco regulatorio que no permite la adecuada diversificación de riesgos y la sana competencia en el mercado se vuelve aparente durante la crisis. Muchas veces, las autoridades se abocan a eliminar regulaciones que inhiben el sano desarrollo de largo plazo del sector. El país que más ha avanzado en la desregulación financiera es Japón.

En Japón, en 1996 se aprueban varias leyes (el conjunto de las mismas se denomina "Big Bang") tendientes a eliminar restricciones sobre la operación eficiente del sistema financiero: i) se elimina el sistema de bancos autorizados para operaciones cambiarias; ii) se eliminan los controles de capital (abril de 1998); iii) se permite la creación de grupos financieros (finales de 1998); iv) se permite a los bancos vender fondos de inversión en mercados extrabursátiles (finales de 1998); v) se pueden cambiar los créditos por títulos colateralizados (finales de 1998); vi) se permite a los bancos comerciales emitir deuda de largo plazo (finales de 1999); vii) se eliminan los controles a las subsidiarias de títulos bancarios (finales de 1999) y; viii) se permite a los bancos vender algunos seguros (2001). Además, se facilita a las instituciones financieras deshacerse de malos créditos mediante su bursatilización.

Por otro lado, las crisis bancarias merman aún más el capital de las instituciones de crédito. Es común encontrar instituciones con baja capitalización e instituciones en poder del gobierno. Las autoridades fuerzan a las instituciones con baja capitalización a someter planes de capitalización. Por su lado, el gobierno se quiere deshacer de las instituciones de crédito en su poder vía su venta a un inversionista o su fusión con algún banco. Para el mejor logro de estos objetivos, las autoridades comúnmente disminuyen los límites a la inversión extranjera, de tal manera que los inversionistas extranjeros puedan adquirir una parte mayoritaria en las instituciones de crédito. Tal es el caso de Corea y Tailandia que aprobaron esas reformas durante 1998. 


\subsection{Ley de Quiebras}

Otro elemento de las reformas que se han llevado a cabo en los países bajo estudio, es la reforma a la ley de quiebras. Dos elementos importantes de los esquemas de venta de cartera involucran la adjudicación de bienes que se otorgaron como colateral de los préstamos y la disposición de los activos de empresas que pasan a manos del gobierno una vez que éste asume sus pasivos. Para facilitar el proceso de venta de cartera en poder de las agencias encargadas de administrar y vender dicha cartera, las autoridades reforman las leyes de quiebra.

En Tailandia, para facilitar la reestructuración de la deuda corporativa, las autoridades reforman en marzo de 1998 las leyes de bancarrota y de disposición de activos. Con las nuevas reformas, una empresa en problemas puede someter a la corte una petición de reorganización. Si se acepta dicha petición, la corte designa a un organizador que tiene que someter un plan de reorganización en no más de tres meses y puede administrar la empresa bajo supervisión de la corte. El plan tiene que ser aprobado por la mayoría de los acreedores.

En Malasia, se reforma la ley de tal manera que si la Agencia de Administración de Activos adquiere el control de una empresa en problemas, tiene la autoridad de designar a un administrador para manejar dicha empresa. El administrador es supervisado por un comité formado por representantes del Ministerio de Finanzas, del Banco Central y de la Comisión de Acciones. El administrador tiene 12 meses para someter un plan de reorganización, durante los cuáles se declara una moratoria sobre las deudas de la empresa. El plan tiene que ser aprobado por un consultor independiente, por la Agencia y por la mayoría de los acreedores.

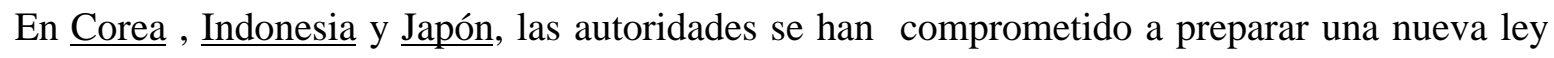
que permita acelerar el proceso de quiebra y de adjudicación de activos.

\subsection{Fortalecimiento de la Autoridad de Supervisión}

Se dota de mayores poderes a la entidad supervisora para que cuente no nada más con los elementos necesarios para hacer una evaluación de la salud de la institución financiera, sino también para que tenga los poderes suficientes para poder sancionar e intervenir a las instituciones en problemas. Además, es común que se reformen las leyes concernientes al contenido de la información sobre la salud de los bancos y a la periodicidad de su publicación. Muchas veces también se dota de mayor independencia a la entidad supervisora existente. Es común que la fortalecida autoridad de supervisión cuente con poderes para: i) sancionar a las instituciones financieras que no cumplan con los requerimientos de publicación de información; ii) intervenir y cambiar la administración de las instituciones con capital insuficiente, y; iii) solicitar la reorganización o liquidación de instituciones financieras en problemas. 


\section{Cuadro 9}

\section{Fortalecimiento de la Autoridad de Supervisión}

En Japón, se crea la Agencia Financiera de Supervisión (ASF) que entra en operaciones el 22 de junio de 1998. La ASF es un órgano separado del Ministerio de Finanzas (pero no cuenta con presupuesto independiente). Esta agencia agrupa la supervisión de todos los tipos de bancos comerciales de Japón. A finales de año la ASF publicará un manual de inspección para las auditorías externas y dará una supervisión continua a las entidades financieras a través de un sistema de cómputo centralizado. Además, mediante una ley que se aprueba en 1996, se permite a la autoridad de supervisión solicitar la reorganización o liquidación de instituciones financieras. Asimismo, por la necesidad de que la administración de las instituciones financieras se sujete en mayor medida a las disciplinas de mercado, se exhorta a las instituciones, analistas y expertos, a que divulguen de forma voluntaria y agresiva la información de las instituciones financieras. Las principales acciones de la ASF hasta la fecha han sido: (i) ordenar a las instituciones financieras que le reporten los resultados de sus autoevaluaciones (las cuales debieron haber terminado en marzo 1998);(ii)realizar conjuntamente con el Banco de Japón inspecciones a los bancos, empezando por los 19 bancos más grandes para después continuar con los bancos regionales.

En Corea, se crea una agencia de supervisión financiera que integra las labores de supervisión de bancos mercantiles y comerciales. En febrero de 1998 se emite una nueva legislación que otorga a la autoridad supervisora facultades claras para cerrar a los bancos insolventes.

En Malasia, aumentan los requerimientos de publicación de información: las instituciones de crédito tienen que publicar trimestralmente su nivel de cartera vencida, la cartera vencida por sector, y el aprovisionamiento y razón de capital sobre activos ajustada por riesgo. En Tailandia, se aumenta la periodicidad con la que el banco central conduce inspecciones in-situ.

\subsection{Auditorías}

En muchas ocasiones, la regulación prudencial y la supervisión mediante el análisis de información publicada, no son suficientes para conocer la situación real de una institución financiera. Esto es todavía más importante en tiempos de crisis, cuando los activos bancarios se deterioran a una velocidad mucho mayor que en tiempos normales. Por lo anterior, las autoridades por lo general aumentan la periodicidad de las inspecciones in-situ, y requieren que las instituciones financieras lleven a cabo auditorías externas periódicamente. Algunos ejemplos de lo anterior son Tailandia que aumenta el número de inspecciones in-situ por parte del banco central, y en Malasia la autoridad de supervisión practica exámenes de sensibilidad mensuales sobre la cartera de instituciones financieras individuales.

\subsection{Autonomía del Banco Central}

De manera coincidente con la aplicación de medidas estructurales para resolver las crisis bancarias y tratar de evitar su recurrencia, se observó que algunos de los países analizados también reformaron las leyes de su banco central. En particular en Corea en marzo de 1998, se decreta la autonomía legal del Banco Central, y en Japón, la Nueva Ley del Banco de Japón entra en vigor en abril de 1998. Dicha ley otorga mayor autonomía al banco central y reduce el papel del Ministerio de Finanzas en la formulación de la política monetaria. Este último deja de tener voto en el Consejo de Política Monetaria pero puede atender las reuniones del Consejo y solicitar una reconsideración de las decisiones que éste tome. El Consejo tiene que operar con mayor transparencia, tiene que publicar las decisiones que tome y las minutas de las reuniones, así como efectuar reportes periódicos a la legislatura. 


\section{Costos Fiscales de la Crisis}

El objetivo de esta sección es cuantificar el costo fiscal de las crisis bancarias que experimentan los países asiáticos objeto de este estudio. Esta medida refleja únicamente el costo para los contribuyentes. Para cada país se toma en cuenta los créditos para inyectar liquidez al sistema financiero, el costo que asume el gobierno en la quiebra de instituciones financieras, así como los costos asociados con la compra y venta de cartera. Cabe destacar que el costo se mide como un porcentaje del PIB. Sin embargo, esta medida no considera la tasa de descuento durante el periodo de amortización, la cual varía entre los países analizados.

\subsection{Japón}

La estimación del costo fiscal en Japón incluye los recursos que el gobierno ha destinado como apoyo al sistema financiero desde 1992 hasta la fecha. Estos recursos son: i) las aportaciones que hicieron el banco central y el Seguro de Depósitos a las 13 instituciones que quebraron entre 1994 a 1996; ii) los recursos para cubrir la pérdida por la quiebra de las jusen; iii) los recursos públicos que el gobierno compromete en octubre de 1998 y que ascienden a un $12 \%$ del PIB. Si se considera que se recuperará la mitad de este $12 \%$, el costo fiscal asciende a $8.8 \%$ del PIB. Este supuesto es razonable si se toma en cuenta que el gobierno capitaliza los bancos a través de la compra de acciones preferenciales las cuales no es de esperarse que pierdan todo su valor (ver detalles de la estimación en el anexo, Japón cuadro IV).

\subsection{Tailandia}

La estimación del costo fiscal en Tailandia considera los recursos que el FIDF ha aportado para créditos de emergencia a instituciones financieras en problemas, que hasta la fecha es del $20 \%$ del PIB. Asimismo, se adiciona la estimación oficial de los costos que asume el gobierno por la adquisición y venta de cartera. Lo anterior resulta en un costo fiscal del $22.7 \%$. Sin embargo, existe el riesgo de que aumente la cartera vencida debido a la recesión económica por la que atraviesa el país. Por otra parte, se debe tomar en cuenta la posibilidad de que se recupere una pequeña parte de los créditos que otorgó el FIDF, por lo que es posible que en realidad el costo fiscal oscile entre 20 y $30 \%$ del PIB. En lo que se refiere al financiamiento de la deuda del FIDF, que es deuda cuasi-fiscal, el gobierno ya declaró que es responsable por toda la deuda y que piensa convertirla en deuda federal a partir del presupuesto de 1998. En 1998, el gobierno emitirá un bono por 500 mil millones de bahts (equivalente a $10 \%$ del PIB), el pago de intereses lo contempla el presupuesto de 1998 y parte de la amortización vendrá del 90\% de las futuras utilidades del Banco Central. El Parlamento aprobó a finales de mayo de 1998 la emisión de dicho bono por parte del gobierno federal.

\subsection{Malasia}

Un elemento fundamental en la estimación del costo fiscal son los créditos de liquidez que hasta la fecha el banco central ha extendido a instituciones solventes e insolventes, y que es equivalente al 13\% del PIB. No obstante, existe la posibilidad de que se recupere parte de estos créditos y que el gobierno inyecte más recursos al esquema de compra de cartera, así como de que exista un costo adicional por las garantías que ofrece el gobierno para cubrir el deterioro de los activos de las instituciones recién fusionadas, por lo que el costo fiscal puede oscilar entre el 10 y $16 \%$ del PIB. 


\subsection{Corea}

Para estimar los costos fiscales de la crisis en Corea se incluyen los recursos que destinó la Compañía de Administración de Activos (CAMCO) para la adquisición de cartera y la inyección de liquidez a los bancos en problemas. Entre diciembre de 1997 y febrero de 1998, CAMCO adquirió un 35\% del total de cartera vencida al $50 \%$ de su valor en libros, y que asciende al 3.8\% del PIB. Asimismo, CAMCO ha realizado inyecciones de capital por montos equivalentes al $0.7 \%$ del PIB, ha adquirido deuda subordinada por un $1 \%$ del PIB y se estima que las inyecciones de capital pueden ascender hasta un $11 \%$ del PIB. De lo anterior, se desprende que el costo fiscal oscila entre $15 \%$ y $20 \%$ del PIB.

\subsection{Indonesia}

Indonesia ha experimentado una crisis social y política, además de bancaria. La inestabilidad de dicha situación y el vacío institucional existente se reflejan en una mayor incertidumbre y un severo debilitamiento del sistema financiero. No existe una estimación confiable del costo fiscal de la crisis debido al alto grado de incertidumbre. Analistas privados estiman que el costo fiscal mínimo será de $20 \%$ del PIB; sin embargo, es muy probable que este costo resulte mayor.

\section{Conclusiones}

Los efectos de la crisis asiática se han resentido en todo el mundo. La crisis financiera ha tenido también repercusiones políticas y sociales. En Japón, el Primer Ministro renunció a mediados de año, en Indonesia después de 32 años en el poder, Suharto se ve forzado a renunciar, y en Malasia el Primer Ministro ha sido cuestionado por primera vez en 17 años. Los efectos adversos de la crisis se han acentuado lo que se ha reflejado en fuertes caídas en los ingresos de la población y en un creciente desempleo.

Existen signos de creciente estabilidad en algunos de los países analizados; especialmente, Japón, Corea del Sur y Tailandia, los cuáles han estado implementado programas de reforma estructural. Estos países han observado a partir de septiembre de1998 una revaluación de sus tipos de cambio y una reducción en sus tasas nominales de interés. Las cuentas corrientes de los países se han tornado superavitarias, aunque esto se debe en gran parte a una caída en sus importaciones. Las reservas internacionales parecen estar repuntando y las obligaciones de deuda externa a corto plazo se han reducido.

Las políticas adoptadas en Japón son determinantes para la recuperación de la región. En este sentido cabe destacar que las predicciones sobre la economía japonesa se han seguido deteriorando durante 1998. Se espera que para el año fiscal de 1998 que termina en marzo de 1999, Japón tenga una contracción de 3\% del PIB y que para 1999 el crecimiento sea nulo. En noviembre de1998, la Organización para la Cooperación y el Desarrollo Económico (OCDE) enfatizó que los paquetes de estímulo fiscal en Japón no garantizan el crecimiento sin la profundización de las reformas estructurales. De acuerdo con la OCDE el crecimiento de la deuda pública puede ser sostenido solamente si las condiciones de crecimiento más robusto a mediano plazo son rápidamente reestablecidas; para esto es esencial agilizar la reforma estructural que si bien se ha avanzado todavía existen deficiencias.

La comunidad internacional ha seguido muy de cerca la evolución de la crisis asiática. A raíz 
de esta crisis se ha discutido la conveniencia de modificar la estructura del sistema financiero internacional; a lo largo de las siguientes ideas: ${ }^{16}$

- Mayor transparencia en el sector privado y público, así como nuevos estándares en los controles internos de las empresas y bancos;

- Mayor vigilancia interna y por las organizaciones multilaterales de las políticas económicas de los países;

- Mayor compromiso de los países para reformar el sector financiero y mejorar los sistemas bancarios y la operación de los mercados financieros para adecuarlos a estándares internacionales;

- Mayor involucramiento del sector privado en la prevención de crisis financieras y en la resolución de las mismas.

En adición a la reforma de la arquitectura financiera internacional, durante 1998 se adoptaron diversas medidas para fortalecer al Fondo Monetario Internacional. Estas medidas son:

a) Se aumentó los recursos de los que dispone el FMI a través de su capacidad para pedir prestado de los países miembros. A través de los "Nuevos Acuerdos para la Obtención de Préstamos" se han establecido líneas de crédito por 48 mil millones de dólares para evitar o enfrentar el menoscabo del sistema financiero internacional o para enfrentar situaciones excepcionales que amenacen la estabilidad de dicho sistema. Estas nuevas líneas de crédito con 25 miembros del Fondo más que duplican los recursos a que anteriormente tenía acceso el FMI. Adicionalmente el Congreso de Estados Unidos aprobó una aportación al FMI por 18 mil millones de dólares. Con esta aportación, el FMI cuenta con alrededor de 90 mil millones de dólares para enfrentar crisis futuras.

b) Se estableció un departamento cuya función es procurar contener el contagio a otros países de la crisis en un país. Esto se espera lograr a través de la concesión de líneas de crédito con aquellos países que mantengan políticas sanas apoyadas por el FMI.

c) El programa del FMI se ha flexibilizado para la resolución de las crisis.

En adición a lo anterior, en la reunión de presidentes del Foro Económico de Cooperación Asia-Pacífico (APEC, por sus siglas en inglés), celebrada en noviembre de 1998, se acordó adoptar los estándares internacionales en materia de supervisión financiera, entre los que se encuentran los "Principios de Basilea para una Supervisión Efectiva" y la legislación de la Comisión de Valores y Cambios de Estados Unidos. También se estableció la importancia de eliminar los impedimentos regulatorios y legales que obstaculicen la participación de las instituciones financieras privadas en la reestructuración de la deuda del sector privado, al mismo tiempo que se incentive a las agencias de crédito para las exportaciones y aseguradoras a participar activamente en la reestructuración del sector.

\subsection{Lecciones de la Crisis Asiática}

1. La crisis de los países de Asia ha demostrado la importancia que tiene el mejorar la transparencia y rendición de cuentas por parte de las instituciones financieras, fortalecer la infraestructura del mercado y fomentar la incorporación del sector privado en la tarea de

\footnotetext{
${ }^{16}$ Neiss, Hubert, "Blueprint for a Bold New Financial Architecture", Fondo Monetario Internacional, 9 de noviembre, 1998.
} 
prevención y solución de las crisis financieras. Por efecto de la elevada movilidad de capitales a nivel global la crisis en los países asiáticos tuvo efectos más allá de sus fronteras afectando el crecimiento de la economía mundial. En un mundo altamente interdependiente es necesaria la adopción de principios internacionales para la supervisión del sistema bancario y del mercados de valores. Esto fue reconocido en la reunión de noviembre de 1998 de presidentes de países miembros de APEC.

2. La regulación de la transparencia de las operaciones de las instituciones financieras y la regulación que responsabilice a sus directivos de la veracidad de la información de las instituciones que dirigen, son elementos cruciales de una estrategia para contener los riesgos de las instituciones. Esta regulación tiene que complementarse con la regulación prudencial (mínimos de capital, liquidez, etc.). En los países asiáticos analizados ambos tipos de regulación y en especial su aplicación fueron deficientes. Para garantizar una adecuada supervisión por parte de las autoridades es indispensable que éstas tengan la capacidad necesaria, que exista una rendición de cuentas estricta de la autoridad de supervisión y que su operación sea plenamente transparente para las instituciones que supervisan y para la sociedad.

3. En las experiencias analizadas los gobiernos terminaron garantizando a los depositantes aún en los casos en que no existía un seguro de depósitos explícito. Los esquemas de garantías implícitos subsidian a las instituciones financieras más riesgosas, esta situación contribuye a que el sistema financiero asuma riesgos excesivos. Este problema no se resuelve con seguros de depósito explícitos en los que las primas del seguro de depósito no se ajustan adecuadamente por el riesgo que asumen las entidades aseguradoras el cual depende del estado de salud de los distintos bancos. Con un seguro de depósitos explícito se debe eliminar el subsidio cruzado que comúnmente existe en estos sistemas de las instituciones financieras mejor administradas y menos riesgosas a las peor administradas y más riesgosas.

Para lograr lo anterior consideramos que la regulación de las entidades que presten el servicio de seguro de depósitos deben sujetarse a los siguientes principios: 1) prohibir a dichos aseguradores fijar primas que impliquen subsidios cruzados entre bancos. Para ello es indispensable dar a los seguros de depósito flexibilidad para cobrar primas diferenciadas; 2) contar con una base de capital propio suficiente para garantizar el pago a los depositantes; 3 ) estar sujetas a un régimen de supervisión que verifique adecuadamente la inexistencia de subsidios; 4) estar sujetas a regulación tarifaria en la medida que no exista una competencia efectiva entre entidades aseguradoras de depósitos. Además, se debe establecer que las aseguradoras de depósitos que inyecten recursos para solventar las obligaciones que los bancos han contraído con los depositantes que sean acreedores de máxima prelación de los mismos. Esto es con el fin de no retrasar la inyección de recursos por parte de las aseguradoras, pues ello puede dar lugar a corridas bancarias no deseadas.

4. Las agencias calificadoras cumplen dos funciones. Evalúan el riesgo soberano de los países y el riesgo de las instituciones financieras. En relación a la evaluación de riesgo soberano son las políticas de deuda de los gobiernos de los países los que son calificados por estas agencias. Desde el punto de vista de la prevención de crisis bancarias y para el sano desarrollo del sistema financiero es importante el desarrollo de sistemas de calificación de las instituciones financieras. Una adecuada calificación inhibe la toma de riesgos excesiva y por tanto la probabilidad de crisis futuras. Para que las calificadoras puedan cumplir con estas funciones es necesario que la regulación contemple la obligatoriedad de que las instituciones financieras sean calificadas periódicamente y que dicha calificación sea 
publicada sin retraso. La calificación de los bancos y la publicación de la información que sirvió de base para emitir tal calificación facilita la determinación de primas actuarialmente justas para el seguro de depósitos y permite a inversionistas, consumidores de servicios financieros y a otras instituciones financieras obtener mejores estimaciones de los riesgos que corren al realizar transacciones con las instituciones financieras calificadas. La supervisión realizada por las calificadoras reforzaría la supervisión de las entidades aseguradoras, los depositantes, los inversionistas y la realizada por las propias autoridades de supervisión. La calificación periódica facilitaría que las instituciones de seguro de depósitos fijaran primas sin subsidios propiciando la viabilidad de dichas instituciones en el largo plazo.

5. La falta de un adecuado control interno de riesgos en los bancos causa problemas de concentración de créditos, un alto grado de créditos relacionados, e incluso la existencia de prácticas fraudulentas. Para la prevención de crisis futuras es preciso que las instituciones financieras adopten mecanismos de control que impidan una toma de riesgos desmedida y que los directivos de dichas instituciones sean responsables de la implantación de dichos controles. Las instituciones deben publicar los niveles de riesgo a que están expuestas y sus directivos deben responsabilizarse por la exactitud de dicha información.

6. En los países estudiados se observa una deficiencia en las leyes de quiebras y en su aplicación. Por lo general, estas leyes impiden una eficiente reasignación de activos y encarecen la resolución de las crisis financieras. La reforma de las leyes de quiebras ha sido una prioridad para acelerar el proceso resolutorio y acotar el costo de crisis futuras; actualmente dichas leyes están en un proceso de revisión en algunos de los países analizados. 


\section{BIBLIOGRAFIA}

Banco de Japón, Reporte Anual, 1995, 1996.

Banco de Japón, "Statement by the Governor Concerning the Merger of Midori Bank with Hanshin Bank", Japón, mayo 15 de 1998.

Banco Mundial, "Indonesia in Crisis: A Macroeconomic Update”, 1998.

Banco Mundial, “Indicadores del Desarrollo Mundial 1997”, Washington D.C., 1997.

BBC News, "Meltdown in Asia - part 1: The origins of the Crisis", julio 2 de 1998.

Bloomberg, Financial Markets Commodities and News, "Bank of Korea Today: Bloomberg Bank Watch", julio 8, 1998.

Bloomberg, Financial Markets Commodities and News, "Japanese Proposal to Set Up Public Banks: An Outline", julio 2 de 1998.

Bloomberg, Financial Markets Commodities and News, "Korea Urges Banks to Cut Rates; Koomin Obliges”, julio 8 de 1998.

Bloomberg, Financial Markets Commodities and News. "South Korean Government Urges Banks to Cut Lending Rates", julio 7 de 1998.

Bloomberg, Financial Markets Commodities and News. "Japan's Political Leaders Agree on Larger Bank Aid", 12 de octubre de 1998

Bloomberg, Financial Markets Commodities and News. "Japan's Lower House Approves Legislation to Rescue Ailing Banks", 13 de octubre de 1998

Bloomberg, Financial Markets Commodities and News. "Japan's 60 Tln Yen Plan Wins DIET Approval", 13 de octubre de 1998

Bloomberg, Financial Markets Commodities and News. "Japan's PM Wants to Give Healthy Banks 20 Tln Yen”, 13 de octubre de 1998

Bloomberg, Financial Markets Commodities and News. "Japanese Bank Head Says Few Need Government Funds", 14 de octubre de 1998

Bloomberg, Financial Markets Commodities and News. "Japanese Economic Panel Urges More Funds for Viable Banks", 14 de octubre de 1998

Bloomberg, Financial Markets Commodities and News. "Hayami Says Policy Unchanged as Stimulus Steps Judged", 15 de octubre de 1998

Bloomberg, Financial Markets Commodities and News, "Bank of Japan Today: Bloomberg Central Bank Watch”, 15 de octubre de 1998 
Bloomberg, Financial Markets Commodities and News, "Japan's Financial Watchdog to Find LTCB Insolvent", 15 de octubre de 1998

Bloomberg, Financial Markets Commodities and News, "Japan Approves Bank Bills, Urges Lenders to Use Funds", 16 de octubre de 1998

Bloomberg, Financial Markets Commodities and News, "Obuchi Says No Extra Diet Planned for Stimulus Package", 16 de octubre de 1998

Bloomberg, Financial Markets Commodities and News, BOJ Minute, 16 de octubre de 1998

Bloomberg, Financial Markets Commodities and News, “Japan's Financial Watchdog Finishes LTCB Audit", 19 de octubre de 1998

Bloomberg, Financial Markets Commodities and News, “Japan’s Miyazawa Reluctant to Force Capital Injections on Banks", 19 de octubre, 1998

Bloomberg, Financial Markets Commodities and News, “Japan to Lend China 390 Billion Yen for Eco-Projects", 21 de noviembre de 1998

Bloomberg, Financial Markets Commodities and News, "Japan Mulls Further 5 Trillion Yen Loans to Asia, Official Says", 23 de noviembre de 1998

Bloomberg, Financial Markets Commodities and News, "Japan to Provide 5 Tln Yen Loans to Southeast Asia, Asahi Says", 23 de noviembre de 1998

Bloomberg, Financial Markets Commodities and News, "Japan's Parliament to Debate Economic Stimulus Plan ”, 26 de noviembre de 1998

Bosworth, Barry, "The Asian Crisis in Context”, presentado en la Conferencia del WhartonLong Term Credit Bank, Tokio, Japón, marzo 10 de 1998.

Brooks, Nick. "Malaysia: Disaster Scenario Builds" en Macro Viewpoint, Santander Investment, octubre, 1998.

Camdessus, Michel, "La economía global: ¿aún en crisis?, preparado para el Congreso Financiero Internacional, Finantia '98, Madrid, Fondo Moneatrio Internacional, 25 de noviembre, 1998.

Carta de Intención del Gobernador del Banco de Corea y del Ministro de Finanzas y Economía de Corea al FMI, Seúl, Corea, diciembre 24 de 1997.

Carta de Intención del Gobernador del Banco de Corea y del Ministro de Finanzas y Economía de Corea al FMI, Seúl, Corea, mayo 2 de 1998.

Carta de Intención del Gobernador del Banco de Tailandia y del Ministro de Finanzas de Tailandia al FMI, Bangkok, Tailandia, noviembre 25 de 1997. 
Carta de Intención del Gobernador del Banco de Tailandia y del Ministro de Finanzas de Tailandia al FMI, Bangkok, Tailandia, febrero 24, 1998.

Carta de Intención del Gobernador del Banco de Tailandia y del Ministro de Finanzas de Tailandia al FMI, Bangkok, Tailandia, mayo 26 de 1998.

Centro de Economía Internacional, "La Economía Mundial: Japón” en Coyuntura Internacional, AÑO4. No.38, septiembre-octubre, 1998.

CITICORP, "Republic of Korea: Upgrade Story Based on Reform and Recovery", Global Research, junio 15, 1998.

Comité para la Administración de la Crisis Financiera de Japón, "Capital Injection”, marzo 1998.

“Corea: Un Gigante Enfermo”, en REFORMA, jueves 23 de julio de 1998.

Corrigan, Gerald, "Sovereign Financial Crises: Facing Realities and Building a More Secure Future", Goldman Sachs, mayo, 1998.

Deutsche Bank Research, "Global Emerging Markets", en Emerging Markets Research, junio, 1998.

Feldman, Robert A., "Japan: Leading Horses to Water" en Morgan Stanley Dean Witter, 13 de octubre, 1998.

Fries, Steven, "Japanese Banks and the Asset Price "Bubble", Documento de Trabajo, FMI, noviembre, 1993.

Fondo Monetario Internacional, "IMF Concludes Article IV Consultations with Korea”, Press Information Notice (PIN) No. 98/39, junio 19 de 1998.

Fondo Monetario Internacional, "IMF Concludes Article IV Consultations with Thailand", Press Information Notice (PIN) No. 98/44, junio 25,1998.

Fondo Monetario Internacional, "IMF Concludes Article IV Consultations with Malaysia", Press Information Notice (PIN) No. 98/31, abril 27,1998.

Fondo Monetario Internacional, "Japan- Staff Report for the 1998 Article IV Consultation", julio 14, 1998.

Fondo Monetario Internacional, "Thailand- Staff Report for the 1998 Article IV Consultation and Third Review Under the Stand-By Arrangement", mayo 26, 1998.

Fondo Monetario Internacional, “Thailand- Selected Issues”, mayo 27, 1998.

Fondo Monetario Internacional, “The IMF’s Response to the Asian Crisis”, junio 15, 1998. 
Fondo Monetario Internacional, "Malaysia- Staff Report for the 1998 Article IV Consultation", marzo 27, 1998.

Fondo Monetario Internacional, "IMF's New Arrangements to Borrow Enter into Force", 19 de noviembre, 1998

Fukao, Mitsushiro, "Japanese Financial Instability and Weakness in the Corporate Governance Structure", Faculty of Business and Commerce, Keio University, 1998.

Goldman Sachs, "Restructuring and Recovery, One Year Later: Where Asia Stands, Where is it Heading”, en Portfolio Strategy, julio de 1998.

Goldman Sachs, "Indonesia- Credit Outlook for the Short Term Remains Troubled", en Fixed Income Sovereign Ratings Focus, 11 de agosto, 1998.

Goldman Sachs, "Malaysia Goes for Capital Controls", en Emerging Markets Biweekly, 9 de septiembre, 1998.

Goldman Sachs, Japan Daily Economic Update, 3 de agosto, 1998.

Goldman Sachs, Japan Daily Economic Update, 6 de agosto, 1998.

Goldman Sachs, Japan Daily Economic Update, 12 de agosto, 1998

Goldman Sachs, Japan Daily Economic Update, 26 de agosto, 1998

Goldman Sachs, Japan Daily Economic Update, 2 de septiembre, 1998

Goldman Sachs, Japan Daily Economic Update, 25 de septiembre, 1998

Goldman Sachs, Japan Daily Economic Update, 29 de septiembre, 1998

Goldman Sachs, Japan Daily Economic Update, 5 de octubre, 1998

Goldman Sachs, Japan Daily Economic Update, 6 de octubre, 1998

Goldman Sachs, Japan Daily Economic Update, 13 de octubre, 1998

Goldman Sachs, Japan Daily Economic Update, 19 de octubre, 1998

Goldman Sachs, "Japan Economic Data Briefing: April-June Quarter GDP, Weak Point Here and There" 11 de septiembre, 1998.

Goldman Sachs, "Quantitive Easing Moves to Center Stage" en Japan Economics Analysts, 18 de septiembre, 1998.

Goldman Sachs, "Bad-Debt Resolution: Credit Contraction and Private-Sector Capex” en Japan 
Economics Analysts, 25 de septiembre, 1998

Goldman Sachs, "Agreement on Recapitalization of Solvent Institutions: Implications for the Economy and Financial Markets", 13 de octubre, 1998

Hanna, D. And Li, D., Asia Economics Analyst, Goldman Sachs, julio, 1998

Hanna, D. And Li, D., Asia Economics Analyst, Goldman Sachs, agosto, 1998.

Hanna, D. And Li, D., Asia Economics Analyst, Goldman Sachs, septiembre, 1998

Indonesia Memorandum of Economic and Financial Policies, Jakarta, Indonesia, junio 24, 1998.

“Indonesia: Un Tropiezo Hecho Pesadilla”, en REFORMA, miércoles 22 de julio de 1998.

InfoSel Financiero, DJ Emerging Markets Report: Indonesia, 22 de octubre de 1998.

|InfoSel Financiero, Noticias Generales- Resto del Mundo: Japón (varias), octubre y noviembre 1998.

InfoSel Financiero, DJ Emerging Markets Report, “Text of APEC Leaders' Statement”, 18 de noviembre 1998.

InfoSel Financiero, DJ Emerging Markets Report (varias), noviembre 1998.

Ito, Takatoshi, "Capital Flows in East and Southeast Asia" presentado en Woodstock Conference on International Capital Flows of the NBER, octubre 17-18, 1997.

“Japón anuncia superpaquete de estímulos económicos por 196 mil mdd" en El Financiero, martes 17 de noviembre de 1998.

JP Morgan, “Japan” en Research Economics, 9 de octubre, 1998.

Kyodo News. “Lending by Japan’s Banks down 2.7\% in Sept.”, Tokio, 14 de octubre, 1998.

Lehman Brothers, Global Markets Daily Strategy, 5 de octubre de 1998.

Lehman Brothers, Global Markets Daily Strategy, 13 de octubre de 1998.

Mcfarland, Mack, "Japan: The Yen- Short Covering, Reform and Dollar Weakness", en Macro Viewpoint, Santander Investment, 8 de octubre de 1998.

Ministerio de Finanzas de Japón, "On the Banks' Self-Assessment Result of Asset Quality", Japón, enero 12, 1998.

Ministerio de Finanzas de Japón, "Outline of the New Approach of Financial Institution 
Inspection”, Japón, 31 marzo, 1998.

Ministerio de Finanzas de Japón, " Outline of the Emergency Measures to Stabilize the Financial System”, Japón, 1998.

Ministerio de Finanzas de Japón, "Comprehensive Plan for Financial Revitalization (Second Report)", Japón, julio 2, 1998.

Ministerio de Finanzas de Japón, "Gist of the Emergency Economic Measures”, Japón, noviembre, 1998.

Mitsubishi Bank, "Mitsubishi Bank Announces Basic Structure of Purchasing Entity", News Release, octubre 30, 1992.

Miura, Mitsuo, "Economic Forum/Finance Reform Bills just the start- Politicians must do much more" en The Daily Yomiuri, 14 de octubre, 1998.

Nagashima, Akira, "Role of the Central Bank During Problems of Bank Soundness: Japan's Experience", Charles Enoch y John. Green (eds.), en Banking Soundness and Monetary Policy, IMF, 1997.

Naito, Junichi, "Introduction of Prompt Corrective Action", Reporte de un Administrador en Kinyu Journal, abril, 1997.

Neiss, Hubert, "Blueprint for a Bold New Financial Architecture", Fondo Monetario Internacional, 9 de noviembre, 1998.

Nikei News, “Japan govt may force banks to accept funds injection”, 14 de octubre, 1998.

Ortiz, Guillermo, "What Lessons Does the Mexican Crisis Hold for Recovery in Asia?", Finance and Development, IMF, junio de 1998.

Organización de Cooperación para el Desarrollo y la Economía, "OECD Economic Survey: Japan”, OECD Economic Surveys 1996-1997, noviembre 1997.

Radelet, Steven y Jeffrey Sachs, “ The Onset of the East Asian Financial Crisis", Harvard Institute for International Development, Cambridge, 1998.

Radelet, Steven y Jeffrey Sachs, "The East Asian Financial Crisis: Diagnosis, Remedies, Prospects", Harvard Institute for International Development, Cambridge, 1998.

Robinson, Gwen, “Tokyo Now Puts Banks’ Bad Debt at \$250bn”, en Financial Times, 18/19 de julio de 1998.

Shimbun, Yomiuri, "Obuchi to pump 20 trln yen into healthy banks" en The Daily Yomiuri, 14 de octubre, 1998.

Shirazi, Javad, "The East Asian Crisis: Origins, Policy Challenges and Prospects", presentado en la Conferencia del Buró Nacional de Investigación Asiática y del Instituto de Estudios Estratégicos, junio 9-10, 1998. 